
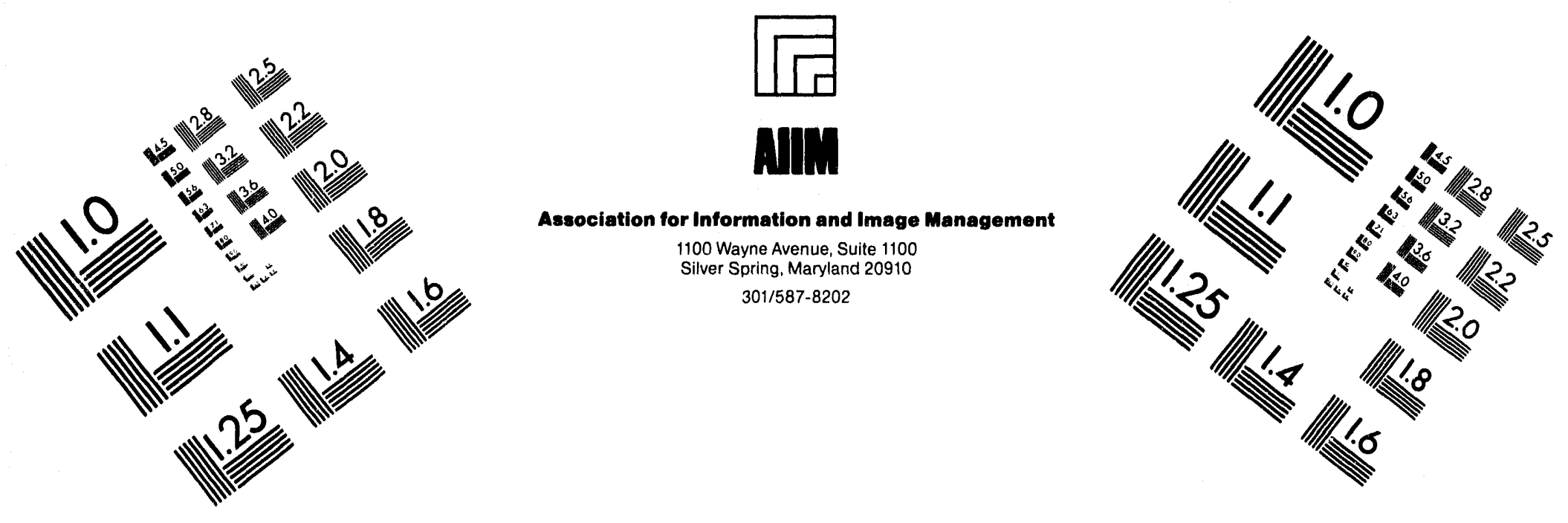

\title{
Centimeter
}

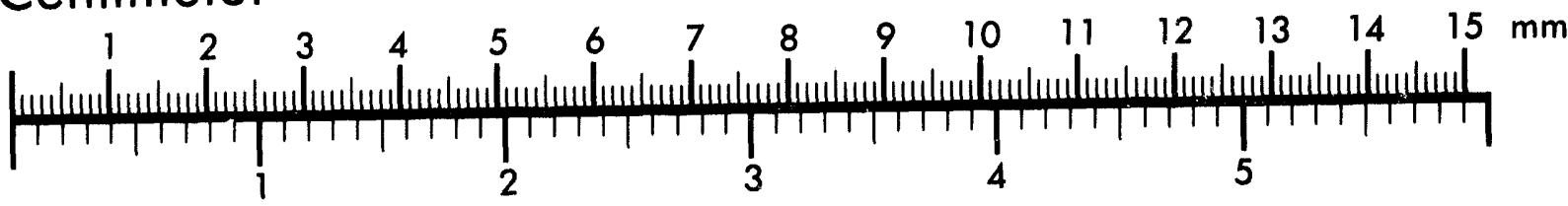
Inches
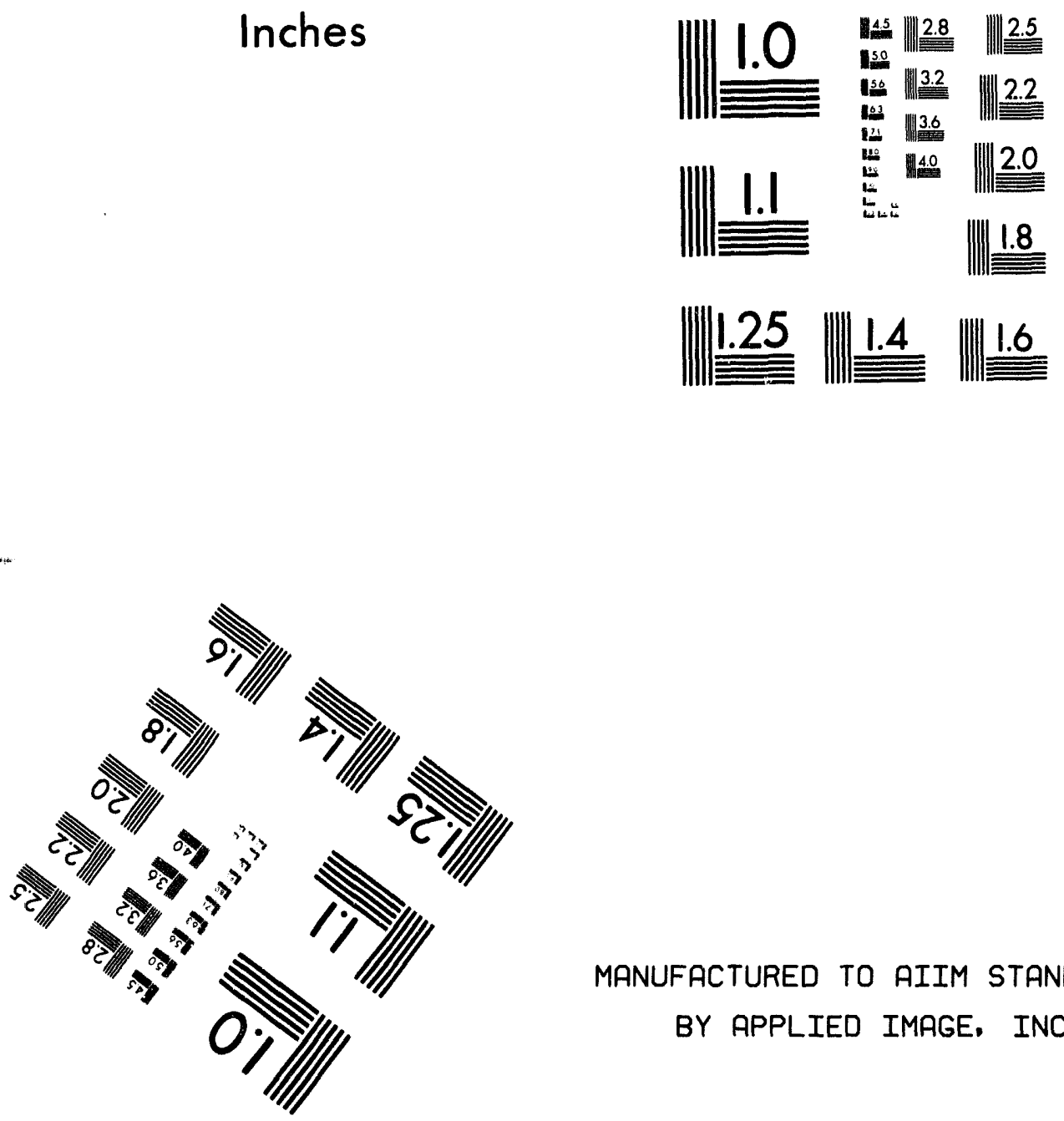

MANUFACTURED TO AIIM STANDARDS

BY APPLIED IMAGE, INC.

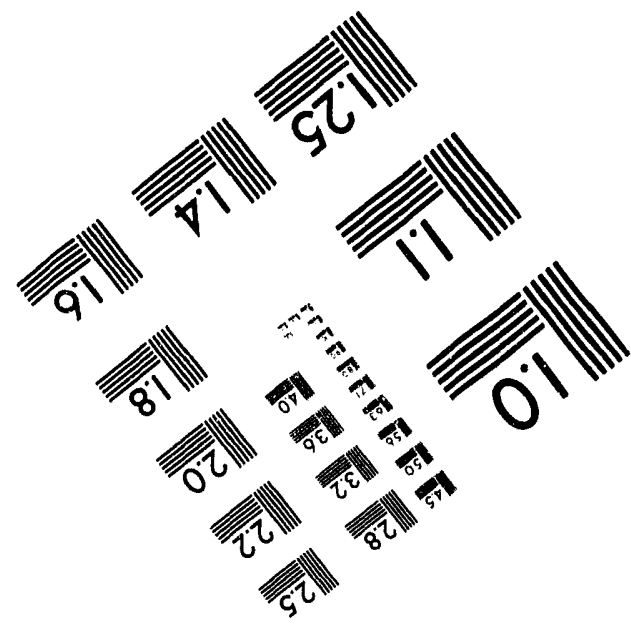



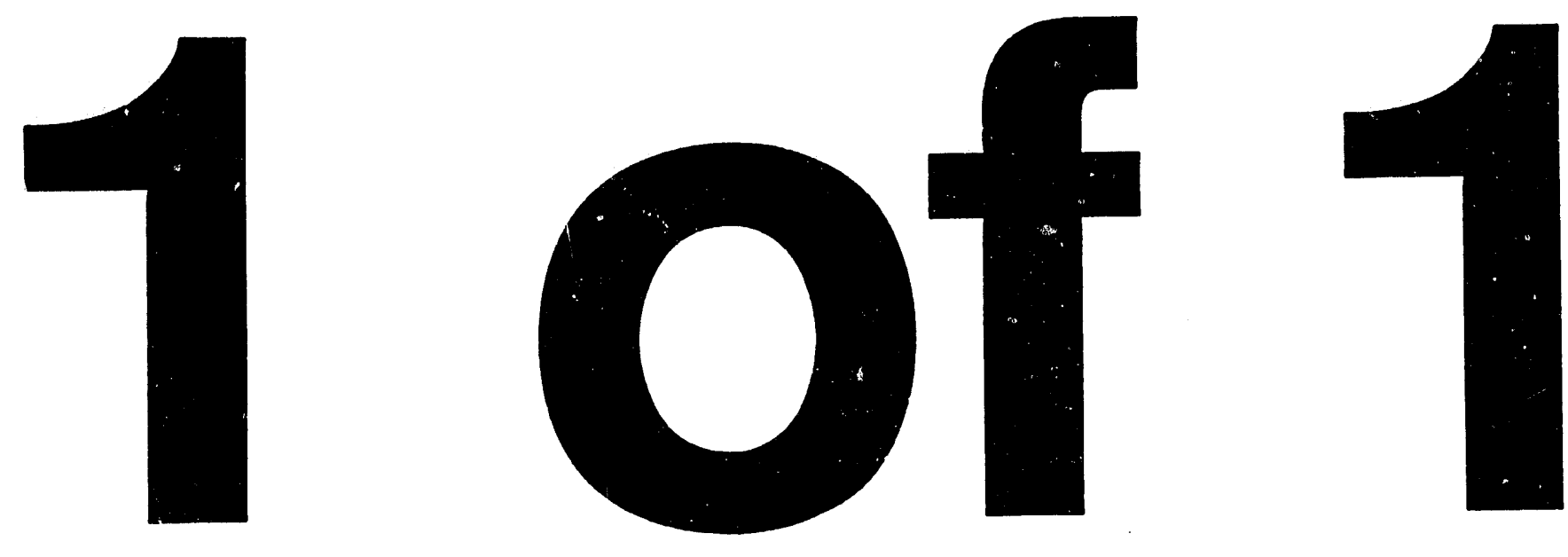


\title{
An Experimental Study of the Hydrodynamics and Cluster Formation in a Circulating Fluidized-Bed Riser
}

\section{Semi-Annual Report}

July 1 - December 31, 1992

\author{
M. Gautam \\ J. T. Jurewicz \\ E. K. Johnson \\ Y. Heping
}

January 1993

Work Performed Under Contract No.: DE-FC21-87MC24207

For

U.S. Department of Energy

Office of Fossil Energy

Morgantown Energy Technology Center

Morgantown, West Virginia

By

West Virginia University

Mechanical and Aerospace Engineering

Morgantown, West Virginia 


\section{DISCLAIMER}

This report was prepared as an account of work sponsored by an agency of the United States Government. Neitber the United States Government nor any agency thereof, nor any of their employees, makes any warranty, express or implied, or assumes any legal liability or responsibility for the accuracy, completeness, or usefulness of any information, apparalus, product, or process disclosed, or represents that its use would not infringe privately owned rights. Reference herein to any specific commercial product, process, or service by trade name, trademark, manufacturer, or otherwise does not necessarily constitute or imply its endorsement, recommendation, or favoring by the United States Govermment or any agency thcreof. The views and opinions of authors expressed herein do not necessarily state or reflect those of the United States Government or any agency thereof.

This report has been reproduced directly from the best available copy.

Available to DOE and DOE contractors from the Orfice of Scientific and Technical Information, 175 Oak Ridge Turnpike, Oak Ridge, TN 37831; prices available at (615) 576-8401.

Available to the public from the National Technical Infomation Service, U.S. Department of Commerce, 5285 Port Royal Road, Springfield, VA 22161; phone orders accepted at (703) 487-4650. 
An Experimental Study of the Hydrodynamics and Cluster Formation in a Circulating Fluidized-Bed Riser

Semi-Annual Report

July 1 - December 31, 1992

\author{
M. Gautam \\ J. T. Jurewicz \\ E. K. Johnson \\ Y. Heping
}

Work Performed Under Contract No.: DE-FC21-87MC24207

\author{
For \\ U.S. Department of Energy \\ Office of Fossil Energy \\ Morgantown Energy Technology Center \\ P.O. Box 880 \\ Morgantown, West Virginia 26507-0880 \\ By \\ West Virginia University \\ Mechanical and Aerospace Engineering \\ P.O. Box 6064 \\ Morgantown, West Virginia 26506
}

January 1993 
SUMMARY

A novel gas-solid flow measuring technique is being developed and tested for studying the hydrodynamics inside the riser of a Circulating fluidized Bed (CFB). First of the two aims of the overall program, namely, design, development and testing of the technique to characterize the particle and gas velocities in twophase flows was accomplished in the past year. The second objective, that of making detailed measurements of gas and solid phases in the rises of a cold CFB model to investigate the phenomena of clusters and streamers for different bed operating parameters is being accomplished in the current year.

The differential pressure fluctuations were in order to study the solids cluster formation. of the several factors which lead to differential pressure fluctuations, the solids cluster formation in CFB riser is by far the most important of all. simultaneously, theoretical formulation of the two-phase flow in the CFB riser was initiated. The concept of entropy maximization is being applied to explain the hydrodynamics inside the riser. The results from this study will present a unique detailed description of the complex gas-solid behavior in the CFB riser. 
CHAPTER 1

\section{INTRODUCTION}

There is increasing interest in operating fluidized beds at high gas velocities where gas-solids contacting may be much improved. In the form of a circulating fluidized bed, it has been recognized as a key to efficient gas-solid processing. The several advantages offered by CFB's over the conventional fluidized bed systems such as uniform bed temperature, reduced aggregation and agglomeration have resulted in a recent vote of confidence by the U.S. utility companies.

To date, the understanding of the CFB's and fundamental research into the underlying phenomena of high-velocity fluid beds and systematic compilation of design data is at best sketchy and even the most rudimentary model and correlation which would permit design are lacking. There are three different flow regimes: bubbling, turbulent, and fast fluidization. In the bubbling regime, gas crosses a horizontal section through a fluidized bed by the following mechanisms:

(i) translation of bubble voids, often called visible bubble flow;

(ii) flow through the bubbles relative to them, often called the through flow component;

(iii) interstitial flow relative to the particles in the dense phase;

(iv) net flux of interstitial voids moving with particles. 
Lanneau (1960) was the first to recognize the transition from bubbling to turbulent fluidization and the potential advantages of operating in the turbulent regime. What Kehoe and Davidson (1971) saw as the velocity of the gas flowing through narrow beds of fine powders was a breakdown of the slugging regime into a state of continuous coalescence - virtually a channelling state with "tongues" of fluid darting in zigzag fashion through the bed. Kehoe and Davidson (1971) coined the word "turbulent" to describe this state. They reported that this transition to the turbulent fluidization occurred at a velocity equal to three times the terminal velocity of particles belonging to the smallest cut. The transition from bubbling to turbulent fluidization is gradual and spans a range of gas velocities. Clusters also exist in this stage.

The transport velocity may be regarded as the boundary which divides vertical gas-solid flow into two groups of states. Below it lie the bubbling and the turbulent fluid beds. The bed in general experiences no net flow and remains at the bottom of the holding vessel. Above, lie the transport regimes which encompass a wide range of states from dilute-phase flow to the fast bed condition. This occurs at twenty times the terminal velocity.

The fast bed condition is marked by relatively high solid concentrations, aggregation of the particles in clusters and strands which break apart and reform in rapid succession, extensive backmixing of solid, and slip velocities of the individual particles. A way to create the dense suspension is to circulate the very solid emerging from the top of the reactor to its bottom. 
Currently, the published work in circulating fluidized beds falls short of answering the questions on the intimately interacting gas-solid flow fields and their influence on each other at a localized level in the riser. Therefore, there is little information available to design engineers for use in optimizing fuels, improving reaction rates of increasing combustion efficiencies. The object of the study of the air-solid two-phase flow is to clarify the flow mechanism resulting from interaction between gaseous and solid phases in the riser.

To study the hydrodynamics and cluster formations in a circulating fluidized bed riser, a special probe for measuring pressure drop between a distance has been developed. This technique utilizes a differential pressure probe to measure the fluctuation of the pressure drop. Detailed measurements of gas and solid flows in the riser of a cold CFB will be taken at different operating parameters to study the phenomena of clusters and streamers.

This report outlines the tasks accomplished in the 3 months of the project. A detailed literature review in Chapter 2 is followed by a chapter on the experimental equipment, procedures and various analyses of the techniques adopted for the project. It also describes the design of the components of a CFB (a transport cold model) which has been fabricated (Jan. '91 - Jun. 191) to study the flows in the riser. The CFB model is in the process of being erected. Chapter 4 gives test results and analysis of all the results. 
CHAPTER 2

LITERATURE REVIEW

A review of the published literature has revealed several works on the flow behavior in circulating fluidized beds. Presented here are only the recent investigations into the hydrodynamics of CFB's and the cluster phenomena in the risers.

Bader et al. (1989) conducted tests in the riser of a CFB with FCC catalyst to determine the degree of gas/solid contacting the fast fluidized bed regime using an intrusive sampling probe and helium tracer technique. They concluded that the solid distribution in the riser is of a core-annulus flow type which high velocity dilute phase core is surrounded by slower, denser solid annulus. The solids flux profile in the riser was determined to be parabolic. The solids flux core was 3 to 5 times the average solids flux and the wall flux flows downward 6 to 8 times the average flux in the riser. The radial particle velocity distribution in the riser was found to also be parabolic through the use of a pitot tube. The application of a pitot tube for this purpose is open to question. It was also concluded that there was substantial backmixing of solids in the riser.Bader et al.'s(1989) study is to be the first in which both the radial solids velocities and radial concentrations were determined for riser flow.

Herb et al (1992) measured the local solid mass flux in the riser component of two different circulating fluidized beds. They found that the local time-averaged solid mass flow varied with radial position, elevation total solids mass flow, superficial gas 
velocity and mean solid diameter. Based on solid mass flux and local solid concentration measurements, and on video studies, a physical description of solid flow pheonomena in CFBs was presented. Their experiment verified the core-annulor flow structure in CFB risers.

Rhodes et al (1992) studied the motion of alumina particles in riser of a colà circulating fluidized bed using high speed video camera. They found that at the wall paticles move predominately downwards, aganst the main gas flow. High density groups or swarms of particles typically arch-shaped. The distribution of swarms decent velocities was shown to be affected little by changes in superficial gas velocity over $3-5 \mathrm{~m} / \mathrm{s}$, an imosed mean solids mass flux over the range of $2-80 \mathrm{~kg} / \mathrm{m}^{2} . \mathrm{s}$. Motion of particles in contact with the riser was analysed by indentification of three flow forms; dilute, dense and swarm flow.

Hirama et al (1992) proposed a conceptual flow regime diagram for a circulating fluidized bed riser. They classified flow state into five regimes by qualitative transition lines. They suggested that s-shaped density distribution or dense/dilute region interface appears only at limited conditions in the bubbling and turbulent fluidization regime.

Miller and Gidaspow(1992) studied the hydrodynamics of gassolids flow in a $75 \mathrm{~mm}$ diameter clear acrylic riser with 75 um FCC catalyst particles. Solids concen'ration was measured with an X-ray densitometer. The fluxes were measuered by means of an extraction probe. They also use experimental data to determine the viscosity of suspension and found that the viscosity was a liner function of 
the volume fraction of particles.

Yoshioka et al. (1987) found that the velocity of the fluidized particles could be determined by measuring the deflection of a spring plate inserted into the bed. The bubbles were detected with the aid of a light transmitting probe. The probe detected bubbles by the intensity of the light being transmitted between the two elements of the probe. Yoshioka developed profiles of the velocity ratio of the fluidized particles, of the bubble fraction, and of the ratio of tracer concentration. He found that the bubbles moved upward away from the center of the bed whereas the particles move upward along the center of the bed but downward near the wall with a circulatory motion.

Drahos et al. (1988) Identified three basic flow regimes when the gas velocity was decreased at the given solid feed rate, namely: uniform dilute flow, with particles flowing upwards in a uniform dispersion; dense flow, characterized by the presence of clouds of particles and voids free of solids; and bubbling dense bed, with the accumulation of solids in the bottom part of the column, forming there a dense bed with the distinct upper surface level. These regimes were found by introducing pressure fluctuations.

Berruti and Kalogerakis (1989) developed a mathematical model capable of predicting the two-phase flow characteristics and required only the experimental average voidage profile along the riser and the net solids circulation rate. The model has been tested in different regimes, and the model predictions compared well with experimental results. 
Phodes and Geldart (1989) formulated pressure losses in the riser, primary cyclone, solids control valve, and slow bed. Their model enabled axial density profiles to be predicted. The terms of entrainment from bubbling beds and choking in pneumatic conveying were the basis for this mathematical model.

Kato et al. (1989) measured the axial particle holdup and the axial pressure drop in a fast fluidized bed. They concluded that the superficial circulation rate of particles, tube diameter, particle Reynolds number, and axial distance from distributor affected the particle holdup. An empirical equation for the location of the inflection point between the dense and dilute region of particles and an empirical equation for particle holdup in a fast fluidized bed were obtained.

Biswas et al. (1987) checked the validity of published choking correlations. By controlling and measuring gas and solid flowrates independently, it was shown that it was possible to delineate the limiting operating flowrates for the fast-fluid bed regime and to obtain a quantitative flow regime defining the limits of fast fluidization. The transition gas velocity was defined as the upper critical gas velocity. For a given solid flux, the upper critical gas velocity represents the highest gas velocity for operation in the fast fluidization mode. The Yousfi and Gau (1974) correlation underpredicts the upper critical velocity by between 15 and 25\%, depending on the magnitude of the solid gas flux. The transition from lean-phase conveying to fast fluidization was found to be analogous to the so-called choking transition in pneumatic conveying. 
Carey (1987) goes over the early work of Richardson and zaki (1954) which gave a relation between concentration and the settling velocity of suspended spherical particles. He also derived equations to define the $\mathrm{n}$ term in the Richardson and zaki equation.

Dry (1986) developed an experimental technique to examine radial gas concentration profiles. Solids were found to appear to congregate on the outside of the lift pipe - fast bed bend. He found the distance above the grid the gas-only radial profile is fairly flat. He also found that at gas velocities between $2 \mathrm{~m} / \mathrm{s}$ and $4 \mathrm{~m} / \mathrm{s}$, the core/annulus distribution is maintained, but at 6 $\mathrm{m} / \mathrm{s}$ the lean core migrates across the tube to the outer wall. Also, Dry (1987) found that at higher velocities, the course particles tend to concentrate along the wall region. The course particles were observed to move from the top of the bed toward the bottom.

Horio et al. (1989) developed scaling laws for circulating fluidized beds. His theory was based on the clustering annular flow model. Experiments were performed using two geometrically similar CFB cold models. Similarity was assumed since the voidage distributions and the annular flow structures were similar and so were the cluster voidages.

Salem and Gibbs (1987) investigated the feasibility of a circulating system, where the driving force for transporting particles is provided by jet pumps. The jets would enable and even distribution of the circulating solids and could also be used to provide a multi-location feeding and withdrawal system. The jets could also be computer controlled to compensate for changes. Salem 
and Gibbs found that large particles were easier to circulate with jets.

Fox et al. (1989) studied the circulation of particles between two fluidized beds for an open-loop circulation. They developed equations to calculate the driving and resisting forces. The authors found that the most efficient way to control the circulation rate of solids was by varying the valve of the vertical resisting force in the downflowing compartment. This adjusts the state of de-fluidization.

Knowlton et al. (1986) discussed the design of lockhoppers which transfer solids from a high-pressure vessel to atmospheric pressure. They found that a restricted pipe discharge system can lower capital cost, giving continuous discharge of solids, and result in a much lower valve maintenance cost. Additionally, the gas requirements were found to be less.

Mountzaris and Jackson (1986) investigated the effects of aeration in standpipes. Their model was based on differential continuity and momentum balances for a system which consisted of a mass flow hopper, a vertical aerated standpipe and a flow restricting device at its lower end. The authors developed equations for the design of each of the above components. With one aeration point, they obtained and discussed twelve flow regimes.

Shingles and Silverman (1986) studied the pressure profile in a stand pipe. Their results showed that the gas compression effect going down the standpipe of the reactor is limited. Sufficient entrapped aeration from the hopper entered the top of the standpipes to enable a fluidized dense-flow regime to exist over 
the entire length of the standpipe.

Extensive reviews of circulating fluidized bed research are presented by Yerushalmi et al. (1979). They concluded that the transition from bubbling to turbulent fluidization is represented by the fluctuations of dynamic pressure at any point across the bed and the pressure drop across the bed. This transition is characterized by velocities $U_{c}$ and $U_{k}$. $U_{c}$ is the velocity at the peak pressure fluctuations and $U_{k}$ is the velocity at which pressure fluctuations level off marking the turbulent regime. Both velocities increase with particle size and density.

The turbulent regime has two interacting phases, dense phase and lean phase, which result in the bed having properties of both individual particles and clusters. Dense phase consists of closely packed clusters and streamers of particles with downward motion. Lean phase is characterized by individual particles and small clusters with upward motion. Yerushalmi et al. (1978) also concluded that the fast bed condition is characterized by high solid concentration, large cluster formations, backmixing of solids, and slip velocities greater than freefall velocities of individual particles by an order of magnitude.

A quantitative discussion and comparison was done by Neale et al. (1972) exploring possible solutions to the problem of creeping flow relative to an isolated permeable sphere. They suggested the most satisfactory solution is based upon a generalized Brinkman's extension of Darcy's Law. It was concluded that internal permeation within a high porosity permeable particle usually cannot be neglected. 
Jackson's (1963) linear stability analysis of dense beds of solid particles operating near minimum fluidization was extended by Grace and Tuot (1979) to apply to more dilute systems. They postulate the origins of particle clusters which occur due to the instability of uniform dispersions of particles in a gas.

Guilin et al. (1984) studied the characteristics of gas mixing a fast. fluidized bed which was $8 \mathrm{~m}$ high, $115 \mathrm{~mm}$ inside diameter, and had a $100 \mathrm{~mm}$ inside diameter downcomer. The bed material was spherical silica-gel particles with a diameter of $0.22 \mathrm{~mm}$. They concluded that the bed could be divided into two regions; the variable voidage zone ( $4 \mathrm{~m}$ from the bottom) and the constant voidage zone. The constant voidage zone is characterized by a constant pressure drop and a uniform axial average voidage. It was revealed that the axial mixing could be neglected.

Yerushalmi et al. (1978) studied the extent of gas backmixing in a catalyst fluidized bed at gas velocities spanning the bubbling, turbulent, and fast bed regimes. The regimes were characterized with high backmixing in bubbling, diminishing backmixing in the turbulent regime, and plug flow in the fast regime.

Lean phase properties were explained with equations for cluster size and terminal velocity by subbarao (1986). Slack (1963) studied the sedimentation of clusters composed of a few particles in a viscous medium.

The effects of hydrodynamic aggregate size, shape, and porosity have upon settling velocity was analyzed by Hamdullahpur et al. (1989). The slip velocity ratio $\left(U_{a} / U_{p}\right)$ was found to 
increase as more particles were incorporated within the aggregate. Hydrodynamic aggregates undergo internal circulation since there are no forces holding particles in position. The forces holding the aggregate together are small and therefore making deformation and disruption easy. They concluded that the relative motion between the aggregate and the fluid results in the fluid passing through of around the aggregate; however, this does not affect the drag coefficient except at high porosities (>0.85).

Sutherland and Tan (1970) applied stoke's solution for flow around a solid sphere to creeping flow outside a permeable sphere and applied Darcy's Law to describe the internal flow. This was in an attempt to obtain limits on permeability for any size aggregate beyond which internal flows may be neglected.

The concept of continuity wave and cluster formation was used to derive a relationship for choking in vertical pneumatic flow by Yang (1983). These relationships were used by Yang (1984) to develop mechanistic models to predict the transitions between the different regimes of fluidization for fine particles. The continuity wave equation was used to predict the transition between bubbling and turbulent regimes. The transition between dilute phase and fast fluidization regimes was approximated using the choking correlations (Yang, 1984).

The computation of bed-solid circulation rates and patterns induced by a central jet and slug motion was performed by Kececioglu (1989). The experiment measured profiles of tracer particles concentrated inside a fluidized bed. 
Cinveris 3

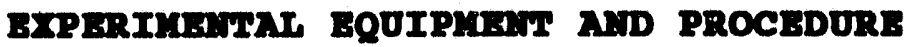

\subsection{Instrumentation and Procedures}

Experiments to determine the voldage distribution in the riser at various solids circulating rates were carried out in the circulating fluidized bed. Two kinds of glass beads with mean diameter of $116 \mu \mathrm{m}$, density of $2305 \mathrm{~kg} / \mathrm{m}^{3}$ and mean diameter of 247 $\mu \mathrm{m}$ density of $2245 \mathrm{~kg} / \mathrm{m}^{3}$ respectively were employed in the experiments. Voidage distributions were obtained as a function of elevation, solids circulations rate, superficial velocity and particle size. A circulating fluidized bed runs at various mass flowrate and at superficial velocity above particle terminal velocity.

Experiments were carried in a lab-scale circulating fluidized bed with a $200 \mathrm{~mm}$ diameter riser, 5.5 meter high riser. As shown in Figure 3.3, the air supply was provided by a compressor with total pressure of 0.1 bar and flowrate of $1370 \mathrm{~m}^{3} / \mathrm{hr}$. The primary air and the aeration air were introduced below the distributor and L-valve. A orifice distributor was employed with a very fine screen to prevent particle from falling through the orifices. The particles entrained by fluidized air and captured by primary and secondary cyclones return to a particle storage hopper via a measuring vessel which provides means for determining the 
solids circulation rates. The returned particles enter the riser through the L-valve and begin another circulation

In the experiments, the superficial velocity was adjusted by primary and aeration air. The solids flowrate discharged into the riser was set by the aeration rate. The solids circulation rate was measured by closing the slide valve under the measuring vessel and recording the time it took for the transparent measuring vessel to fill up with solids. Volume of the measuring vessel is 0.00228 $\mathrm{m}^{3}$. The apparent packed density of the solids was measured to enable the calculation of the solids circulation rates. The flowrate of aeration air was measured by a rotary flowmeter and the primary air flowrate was measured by a DS-200 Flow sensor produced by Dwyer Instruments, Inc.

18 pressure taps were arranged along the height of the riser. In the experiments, superficial velocities ranged from 2.00 $\mathrm{m} / \mathrm{s}$ to $7.33 \mathrm{~m} / \mathrm{s}$. The solids circulation rates are between $10 \mathrm{~kg} \cdot \mathrm{m}^{\text {. }}$ $2 \cdot \mathrm{s}^{-1}$ and $40 \mathrm{~kg} \cdot \mathrm{m}^{-2} \cdot \mathrm{s}^{-1}$.

\subsubsection{ADC Board-- RTI-815}

A multifunction analog/digital input/out board - RTI-815, that plugs into one of the available long expansion slots in the dedicated laboratory computer was employed. It has capabilities for analog I/O, digital I/O, and time-related digital I/O functions. The RTI - 815 supports the measurement of 16 single-ended input signals, 16 pseudo-differential input signals, or 8 differential input signals. It contains a single 12-bit analog-todigital converter $(A D C)$. It can be configured to receive analog 
input voltages with the range of 0 to $+10 \mathrm{~V},+5 \mathrm{~V}$, or $+10 \mathrm{~V}$ using fumpers on the board. It can select straight binary or twos complement digital coding for ADC using fimpers on the board.

The RTI - 815 incorporates a software-selectable monolithic instrumentation amplifier that is used to condition lowlevel signals that the RTI-815 board can measure depends on the input signal range and gain we select as follow:

* 0 to $10 \mathrm{~V}$ range (unipolar) - In this range, the RTI 815 can measure input signals in the follow ranges:

- 0 to $10 \mathrm{~V}$ with a gain of 1

- 0 to $1 \mathrm{~V}$ with a gain of 10

- 0 to $100 \mathrm{mV}$ with a gain of 100

- 0 to $20 \mathrm{Mv}$ with a gain of 500

* $\quad \pm 1-5 \mathrm{~V}$ range(bipolar) - In this range, the RTI 815 can measure input signals in the follow ranges:

$-+/-5 \mathrm{~V}$ with a gain of 1

$-+/-500 \mathrm{Mv}$ with a gain of 10

$-+/-50 \mathrm{Mv}$ with a gain of 100

$-+/-10$ Mv with a gain of 500

* $\quad \pm 1-10 \mathrm{~V}$ range(bipolar) - In this range, the RTI 815 can measure input signals in the follow ranges:

$-+/-5 \mathrm{~V}$ with a gain of 1

$-+/-1 \mathrm{~V}$ with a gain of 10

$-+/-100 \mathrm{Mv}$ with a gain of 100

$-+/-20$ Mv with a gain of 500

Assuming a gain of 1 , the resolution of the analog-to-digital(A/D) 
conversion is 12 bits (4096 counts), which provides a least significant bit(LSB) value of $2.44 \mathrm{mv}$ when in either the 0 to +10 $\mathrm{V}$ or $+/-5 \mathrm{~V}$ range and $4.88 \mathrm{mv}$ when in the $+/-10 \mathrm{~V}$ range.

The standard version of RTI - 815 board is available with an $A / D$ conversion speed of $25 \mu \mathrm{m}$. The $25 \mu \mathrm{m}$ ADC provides sample throughputs of up to 31,000 channels/second on an IBM PC/XT. These sample throughputs are calculated for a single channel at a gain of 1. Table 3.1 lists the different signal ranges, LSB values, and potential sample throughputs for the supported gain selections.

TABLE 3.1 Signal Range, LSB Values, and Sample Throughputs for each Gain setting

\begin{tabular}{||l|c|c|c||}
\hline \multirow{2}{*}{ Gain } & \multicolumn{3}{|c||}{$+/-10 \mathrm{~V}$ Unipolar } \\
\cline { 2 - 5 } & Signal Range & LSB values & $\begin{array}{c}\text { Sample } \\
\text { Throughputs }\end{array}$ \\
\hline 1 & $+/-10 \mathrm{~V}$ & $4.88 \mathrm{mV}$ & $31.2 \mathrm{kHz}$ \\
\hline 10 & $+/-1 \mathrm{~V}$ & $488 \mathrm{uV}$ & $31.2 \mathrm{kHz}$ \\
\hline 100 & $+/-100 \mathrm{mV}$ & $48.8 \mathrm{uV}$ & $25.0 \mathrm{kHz}$ \\
\hline 500 & $+/-20 \mathrm{mV}$ & $9.76 \mathrm{uV}$ & $12.5 \mathrm{kHz}$ \\
\hline
\end{tabular}

Pacer sources for analog to digital conversion was supplied in RTI - 815 board. Using this it is much easy to paces the A/D conversions on the RTI - 815. This gives the feasibility of pacing $A / D$ conversions at precise time intervals or synchronizing 
them with external events. The following sources are supported:

* Software convert command.

* External TTL logic level signal applied to the external convert command input pin of connector.

* AM9513A counter/timer chip on the RTI - 815 programmed to act as a pacer clock to supply a timed series of convert command pulse.

The RTI - 815 contains the circuitry to generate an interrupt when one of the following events occurs:

* An A/D conversion is completed.

* An overrun condition occurs.

* The terminal count of a direct memory access(DMA) high-speed data transfer is reached.

The RTI - 815 board's interrupt circuitry is directly compatible with the interrupt request lines of the IBM PC.

The RTI - 815's analog input circuitry allows high-speed data acquisition from a single channel(collect) or multiple input channels(scan with automatic wraparound when the last channel's conversion is performed). High speed acquisition is used with the DMA and interrupt circuitry of the board. The scan and collect timing is controlled by the pacer output channel of the counter/timer chip.

\subsubsection{Pressure Transducers}

Several P305D pressure transducers manufactured by Validyne Engineering Corp. were installed in the riser. The P305D pressure transducer and carrier demodulator are included in a 
single package to provide a 5 Vdc output with operation from unregulated 10.8 to 32 Vac input power. It is a differential pressure transducer with symmetrical pressure cavities of stainless steel. Fluld pressure act directly on a central diaphragm in a balanced variable reluctance design which eliminates the need for internal isolation fluids. The diaphragm of the transducer is replaceable. The diaphragm-type pressure transducer designs are based on the magnetic-reluctance principle and offer a number of advantages in pressure measurement and control. These include:

1. Excelient dynamic, response characteristics with liquid as gas systems due to high natural frequency, low volumetric displacement and low internal volume.

2. Ability to accept corrosive liquids and gases on both sides for differential pressure measurement without isolation of pickoff mechanism.

3. Extreme overload tolerance -- operator proof.

4. Ability to withstand severe shock and vibration.

5. High level output

6. High nolse immunity.

The following are some important specifications:

$\begin{array}{ll}\text { Accuracy: } & +/-0.25 \% \text { FS, including } \\ & \text { linerity, hysteresis, and } \\ & \text { repeatability. } \\ & 10.8 \text { to } 32 \mathrm{Vdc} 03.7 \mathrm{~mA} \\ \text { Excitation: } & \text { nominal } \\ & 0.015 \% / \mathrm{Volt} \max \\ \text { Line Regulation: } & +1-5 \text { Vdc Fs } 0.5 \mathrm{~mA}\end{array}$




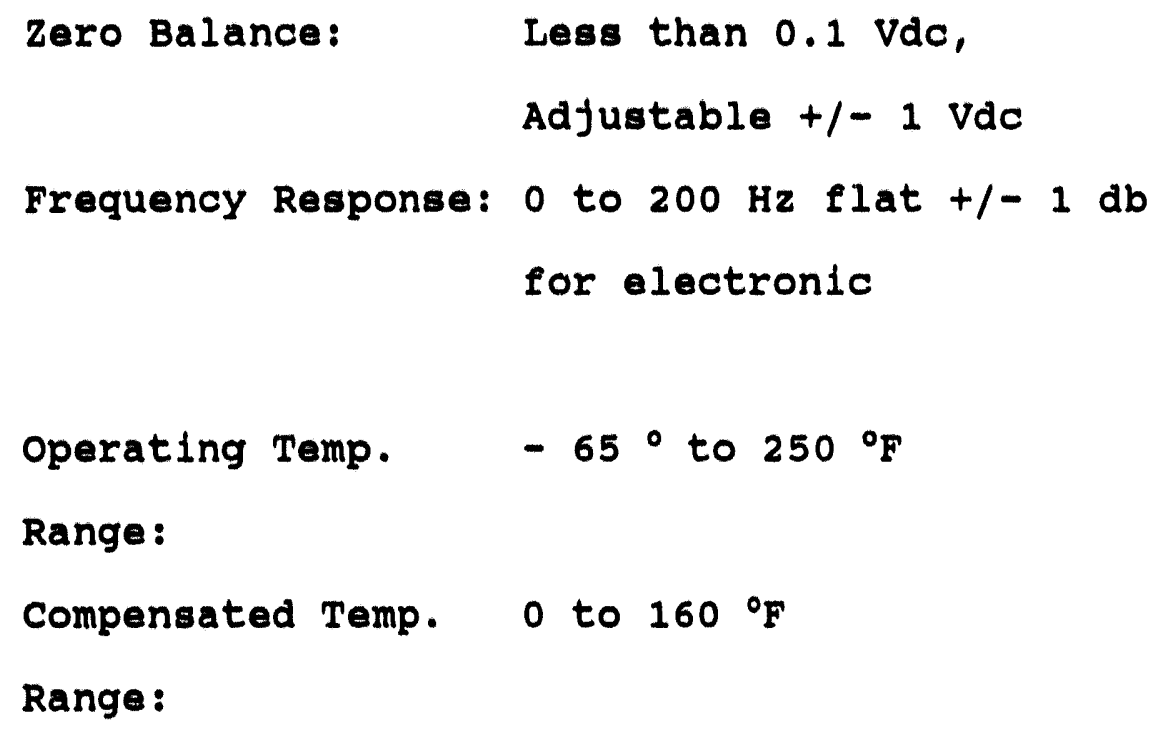

\section{1 .3 PROBES}

A special differential pressure probe, shown in Figure 3.1, was custom built to measure the frequency of solids cluster formation. In a circulating fluidized bed, there is a axial pressure drop in the riser. Barth (1958) has derived equations for pneumatic transportation of solids by a consideration of balance of various forces acting on the particles, the fluid, and the pipe wall. He expresses the pressure drop as

$$
\Delta P=\Delta P_{q}+\Delta P_{g}
$$

Where $\Delta \mathrm{P}_{\mathrm{g}}=$ pressure drop due to the flow of gas alone in the pipe at superficial velocity $v_{s g}$ '

$$
\begin{gathered}
\Delta \mathrm{P}_{\mathrm{s}}=\text { the additional pressure drop caused by the } \\
\text { presence of solids. }
\end{gathered}
$$

and 


$$
\frac{\Delta P_{g}}{\Delta z}=\frac{2 R \rho_{g} V_{g} V_{G Q} L_{g}}{D}+g R \rho_{g} \frac{V_{Q q}}{V_{g}}
$$

since

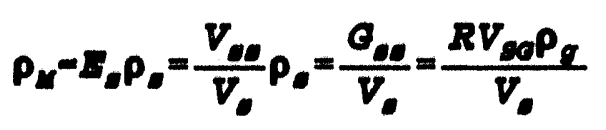

Where

$$
\begin{aligned}
& V_{s}=\text { solid velocity } \\
& V_{g}=\text { gas velocity } \\
& V_{s s}=\text { superficial solid velocity } \\
& V_{s q}=\text { superficial gas velocity } \\
& R=\text { mass flow ratio } \\
& P_{s}=\text { solid density } \\
& P_{g}=\text { gas density } \\
& E_{s}=\text { volume fraction of solid }
\end{aligned}
$$

so, the second term of equation is a hydrostatic head term based on the in situ concentration of solids and neglecting the weight of the gas itself. The first term is the pressure gradient caused by the impact of the particles on the pipe wall.

A special differential pressure probe shown in Figure 3.1, was designed to measure the pressure fluctuation between a vertical distance in the circulating fluidized bed. The distance between two tips is $10 \mathrm{~mm}$ and the solids concentration is

$$
P_{x}=\frac{\Delta P}{g \Delta z}-\frac{\Delta P_{g}}{g \Delta z}-\frac{\Delta P_{1 I}}{g \Delta z}
$$


In a given run condition, the constant superficial velocity $v_{g}$ leads to a constant $\Delta \mathrm{P}_{\mathrm{g}}$. since

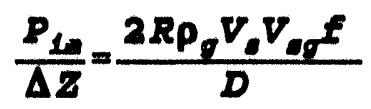

Where $f$ is a solid friction factor.

$\Delta \mathrm{P}_{\text {IM }}$ is the pressure drop caused by particles impact on the wall. For a given opeartion condition, this term shoud be constant.

The sisids concentration fluctuation can be obtained by measuring the pressure fluctuations. The frequency of solids concentration fluctuation is corresponds to the frequency of pressure fluctuation according to above analysis. The solids clusters are described as a group of solids that move en masse undex the influence of hydrodynamics forces(Taweel el ta, 1989). They are believed to form as a consequence of the tendency of multiphase systems to recognize themselves in order to minimize energy dissipation and maximize entropy generation. The solids cluster formation is not a continuous process but a periodic variation.

\section{1 .4 SOFTWARE}

A menu driven software using RTI-815 for data acquisition was developed. It includes three parts: first, the data acquisition board's set up, data acquisition, and data storage; second is the 
display and third is the data analysis. A block diagram of software is shown in Figure 3.2 .

The first part of user-friendly software required inputs such as range of voltages of the analog inputs, number of channels required during the operation, number of data samples needed, sampling frequency and so on.

The second part of software includes two kinds of display modes -- digital display and graphic display. In graphic display option, the $\mathrm{X}$-axle and $\mathrm{Y}$-axle and their scale are set up according to prior inputs of data sampling frequency and data points. In digital display option, the data values such as the value of each channel, the sampling frequency, and time appear as digital values on the screen.

The third part includes a FFT software to analyzed the data which were in stored in hard diver or disk driver. A print function was included in order to print out the output of the analysis.

\subsection{Circulating Fluidized Bed Facility}

A Circulating Fluidized Bed (CFB) experimental set-up was designed (see Figure 3.3) to provide maximum versatility in investigating particle cluster formation in the CFB riser using LDA, optic fiber probes, and other probes. The cold-flow CFB facility has been set-up in the Fluidization center and is currently fully operational. The cold-flow CFB model is $4.5 \mathrm{~m} \mathrm{high}$ and constructed mainly out plexiglas. Two stage cyclones are employed to capture the particles exhausted from the riser. The 
baghouse connected to the outlet of the secondary cyclone prevents fines from being exhausted to the atmosphere. The riser is made of Plexiglas tube with an inside diameter of $200 \mathrm{~mm}$, wall thickness of $8 \mathrm{~mm}$, and consists of 6 jointed sections in order to enhance the versatility of the experimental set-up.

Under normal operating conditions the fluidizing velocity in the CFB varies from $3 \mathrm{~m} / \mathrm{s}$ to a maximum of $12 \mathrm{~m} / \mathrm{s}$. Design air flowrate is $0.25 \mathrm{~m}^{3} / \mathrm{s}$. Circulation of particles varies from 10 $\mathrm{kg} / \mathrm{m}^{2} \mathrm{~s}$ to $200 \mathrm{~kg} / \mathrm{m}^{2} \mathrm{~s}$. At maximum fluidizing velocity, the entrainment capacity of air is $138 \mathrm{~kg} / \mathrm{m}^{3}$, and the mean voidage at outlet of riser is 0.94 .

In order to observe the quality of fluidization and the flow patterns, the riser is made of Plexiglas. Transparent bed wall provides clear access for observing and videotaping gas bubbles, particle clusters, etc., and help in the adjustment of parameters controlling the flow patterns and fluidization.

The CFB experimental set-up was designed as a cold-flow model; however, studies at temperatures above ambient can be performed. The fluidizing air can be heated with electrical heaters up to 100 degrees Celsius. This will be very helpful in studying the formation of clusters as a function of temperature. Design details of each component of the cold-flow CFB system are given below:

\subsubsection{Design of the Distributor}

Published literature has presented ample evidence showing that the quality of fluidization is strongly influenced by the type of 
gas distributor used. For few air inlet openings the bed density fluctuates appreciably at all flow rates, though more severely at higher flow rates. For more air inlet openings the fluctuation in bed density is negligible at low air flow rate. Bed density is more uniform throughout. Since the mean diameters of particle is $50 \mu \mathrm{m}$, the orifice of the distributor must be small enough to maintain the particle. Considering the distributor size, the pressure drop and fluidizing velocity, a orifice type distributor with diameter of $3 \mathrm{~mm}$ covered with a steel screen was employed. At the operating condition the pressure drop across the distributor is $4.2 \mathrm{KPa}$.

\subsubsection{Design of the Riser}

The Diameter of the Riser

Most of the previous investigations (van Zoonen, 1962; Hartage et al. 1986) with a few exceptions (Bader, Findlay, and Knowlton, 1989) employed a small diameter riser (50 mm to $100 \mathrm{~mm}$ ). Experimental results obtained from both the large and the small diameter test units have shown that the flow in the riser of circulating fluidized beds is of a core-annulus type.

The solid and gas interaction between the core and the annulus is an important consideration in the evaluation of risers since the amount of interaction affects the solid and gas residence times. Therefore, tests should be conducted in a unit with suitable size riser in order to determine the mass flux and particle velocity distributions as a function of riser radius and also axial riser position. 
The results of experiments conducted by Bader, Findlay, and Knowlton (1989) have shown that the radial solids flux profile in the riser is parabolic. At a location $9.1 \mathrm{~m}$ above the solids entry poist, the net mass flux rate decreased with riser radial position to a value of zero at about $25 \mathrm{~mm}$ from the wall, and the particle velocity profile is also similar to the mass flux profile. Voidage profile is smoother than both the mass flux and particle velocity profiles. Taking the wall effects and particle-particle interaction into consideration, a riser with a diameter of $200 \mathrm{~mm}$ was selected which 2 times the width of the particle flux region.

\section{Height of the Riser}

Bader, Findlay, and Knowlton (1989) have shown that, the mass flux and voidage profiles at positions of 9.1 and $4.0 \mathrm{~m}$ are nearly the same except for the quantity of mass flux and voidage. For sake of limited space, the height of the riser was selected as 4.5 $\mathrm{m}$ and divided into 6 sections. From bottom to top, the various sections are $700 \mathrm{~mm}, 800 \mathrm{~mm}, 800 \mathrm{~mm}, 800 \mathrm{~mm}, 800 \mathrm{~mm}$. and $600 \mathrm{~mm}$, respectively in length.

\subsubsection{Design of the Cyclones}

circulating fluidized beds are characterized by particle circulation. The circulation of particles depends mainly on the fluidizing velocity and the quantity of particles captured from exhausted gas. If the particles captured from the exhaust gas are much smaller than those in the exhaust gas then a stable circulation cannot be maintained. Hence, provisions are made to 
improve the collection of exhausted particles using a multistage cyclone, baghouse, electrical filters and so on. Considering the actual situation, two stage cyclones are inserted in the experimental set-up and the design details are given below:

\section{Dimensions of the cyclones}

Since the concentration of solids is very high in the outlet of the riser of circulating fluidized bed and it is impossible to capture all the fines from gas-solids mixture by a single cyclone, Two similar standard cyclones are employed in the test unit in order to capture the particles exhausted from the riser as shown in Figure 3.4 The primary cyclone may play a key role in capturing solids from gas-solids mixture to keep mass balance in circulating fluidized bed and second one captures fines which escaped from primary cyclone to prevent environment. The outside diameters of both the cyclones are $300 \mathrm{~mm}$. Diameter of the outlet is $150 \mathrm{~mm}$. Height of the primary cyclone and that of the secondary cyclone is $600 \mathrm{~mm}$. Other dimensions of both of the cyclones are as follows:

$$
\begin{aligned}
& \text { Primary Cyclone secondary cyclone } \\
& D=300 \mathrm{~mm}, A=1200 \mathrm{~mm} \quad D=300 \mathrm{~mm}, A=1200 \mathrm{~mm} \\
& B=600 \mathrm{~mm}, C=600 \mathrm{~mm} \quad B=600 \mathrm{~mm}, C=600 \mathrm{~mm} \\
& E=75 \mathrm{~mm}, \quad F=188 \mathrm{~mm} \quad E=75 \mathrm{~mm}, \quad F=188 \mathrm{~mm} \\
& L=75 \mathrm{~mm}, K=150 \mathrm{~mm} \quad L=75 \mathrm{~mm}, K=150 \mathrm{~mm} \\
& M=150 \mathrm{~mm}, N=38 \mathrm{~mm} \quad M=150 \mathrm{~mm}, N=38 \mathrm{~mm}
\end{aligned}
$$

The inlet velocity of both cyclones is $18.8 \mathrm{~m} / \mathrm{s}$ and the outlet velocity of both is $11.9 \mathrm{~m} / \mathrm{s}$. 


\section{Calculation of Pressure Drop}

The air flowrate is $2.5 \mathrm{~m}^{3} / \mathrm{s}$ and the inlet velocity $v_{c}$ of the cyclone is $18.8 \mathrm{~m} / \mathrm{s}$. The number of cyclone inlet heads $\mathrm{p}_{c}$ :

$$
\begin{aligned}
P_{c}=k_{0} K L / M^{2} & =16.0 \times 150 \times 75 / 150^{2} \\
& =8.0
\end{aligned}
$$

here $k_{0}$ is a constant, for the following conditions, $k_{0}=16.0$

$$
\begin{aligned}
& L / D=1 / 12-1 / 4 \\
& K / D=1 / 4-1 / 2 \\
& M / D=1 / 4-1 / 2
\end{aligned}
$$

The velocity head (in $\mathrm{H}_{2} \mathrm{O}$ ):

$$
h_{v i}=0.05 \times \rho v_{c}^{2}=0.05 \times 1.2 \times 18.8^{2}=21.2 \mathrm{~mm} \mathrm{H} \mathrm{H}_{2}
$$

The total pressure drop across cyclone:

$$
p=p_{c} \times h_{v i}=8.0 \times 21.2 \mathrm{~mm} \mathrm{H} \mathrm{H}_{2} \mathrm{O}=169.6 \mathrm{~mm} \mathrm{H}_{2} \mathrm{O}
$$

The minimum particle size:

$$
D_{p \min }=\left[\frac{9 \mu D}{\pi V_{c}\left(\rho_{s}-\rho\right)}\right]^{1 / 2}=\sqrt{\frac{9 \times 1.2 \times 10^{-5} \times 0.3}{3.14 \times 5 \times 18.8(2000-1.2)}}=7.6 \times 10^{-6} \mathrm{~m}
$$

Here $v_{c}$ is the inlet velocity, $\mu$ is the viscosity, $N$ is the number of turns, $N=5$

The cut size: 


$$
D_{p c}=\sqrt{\frac{9 \mu D}{2 \pi N \nabla_{c}\left(p_{s}-p_{g}\right)}}=\sqrt{\frac{9 \times 1.2 \times 0.3 \times 10^{-5}}{2 \times 3.14 \times 518.8(2000-1.2)}}=5.2 \mu \mathrm{m}
$$

The separation efficiencies are:

$\begin{array}{lcccc}d_{p} & 3 \mu \mathrm{m} & 10 \mu \mathrm{m} & 15 \mu \mathrm{m} & 20 \mu \mathrm{m} \\ \text { efficiency } & 22 \% & 80 \% & 90.5 \% & 99.5 \%\end{array}$

\subsubsection{Design of the Hopper}

A particle hopper employed in the experimental set-up. Since the maximum mass flux rate is $25 \mathrm{~kg} / \mathrm{s}$ in the test unit, there should be enough room to store the circulating particles in the loop to maintain a stable circulation.

Considering the particle circulation to be stable and the time required for each complete circulation in the CFB to be 5 seconds, the quantity of particles passing a given section in the stand pipe, $w$, is $125 \mathrm{~kg}$ per circulation. The hopper was designed to store at least twice this amount. The volume of the hopper, $V$ is $V=2 W / \rho_{B}=2 \times 125 / 2500=0.1 \mathrm{~m}^{3}$, at least assuming the density of particles, $\rho_{\mathrm{s}}$ is $2500 \mathrm{~kg} / \mathrm{m}^{3}$.

\subsubsection{Desion of the L-Valye}

Several types of non-mechanical valves are in use today to transfer the particles from the standpipe to the riser. Notable amongst them are L-valves and U-valves. Importance of a well designed L-valve cannot be overstressed. Depending on the particle characteristics, two types of flows can exist in the non-mechanical valves, namely aerated flow and stick-slip flow. If stick-slip 
flow exists, it is necessary to determine whether there exists a positive pressure difference (pressure at the top is lower than the pressure at the bottom).

From the operating conditions and the particles employed in the test, it is apparent that a stick-silp flow exists in this test. The ideal seal height (where there is a net zero gas flow rate) and the height (where the solids in the leg flow continuously downward) are determined. In the experimental unit, an L-valve is employed. 


\section{CRAPTER 4}

\section{REBULTB AND DIBCU8BION}

Measurements of frequency of solids formation and the voldage profile along the riser were carried out in the circulating fluidized bed riser with a diameter of $200 \mathrm{~mm}$ and height of $4.5 \mathrm{~m}$ using a custom built special differential pressure probe. Two kinds of glass beads with mean diameter of $116 \mathrm{~mm}$, density of $2305 \mathrm{~kg} / \mathrm{m}^{3}$ and mean diameter of $247 \mu \mathrm{m}$ density of $2245 \mathrm{~kg} / \mathrm{m}^{3}$ respectively were employed in the experiments. The experimental results showed that the voldage profile along the riser varied with the elevation, solids circulation rate, superficial velocity and particle size. The particle circulation rate has a significant influence on the voldage profile along the riser. The frequency of solids cluster formation in the riser is less than $2 \mathrm{~Hz}$ at various superficial velocities, solids circulation rates, and locations along the riser. However, there are differences in the frequency of solid cluster formation at different operation conditions.

\subsection{Voidege profile aleng the Riser}

Information on the voldage profile along riser in circulating fluidized bed riser is while designing and operating the circulating fluidized bed systems. The voldage profile along the riser plays a very important role in gas-particle back mixing and influences the solids concentration profiles, solids velocity 
profiles and voldage distribution. These parameters have a direct impact on the gas-solids reactions and heat and mass transfer rates.

An experimental study on the voldage profile along riser was conducted in a lab scale clrculating fluidized bed. The results of the experiments provide insight of solids concentration along the riser in a circulating fluidized bed.

4.1.1. Voidage proflle along a Riser of Circulating Fluidized Bed.

The voldage profile along riser was obtained by time averaged local hydrostatic head at 18 vertical locations at a given operating condition.

Figure 4.1 shows voldage profiles along the riser which were measured at 18 different positions along the riser at different superficlal velocities. And Figure 4.2 shows the voldage profiles along the riser at different solids circulation rates. The superficial velocity was varied from $2.00 \mathrm{~m} / \mathrm{s}$ to $5.5 \mathrm{~m} / \mathrm{s}$. The circulation rates ranged from $1.5 \mathrm{~kg} \cdot \mathrm{m}^{-2} \cdot \mathrm{s}^{-1}$ to $40 \mathrm{~kg} \cdot \mathrm{m}^{-2} \cdot \mathrm{s}^{-1}$. These figures show that at constant solids circulation rate the voldage profile resembles a "power law" distribution and when the superficial velocity increases the voldage profile is going to be fuller. Howevar, for increasing solids circulation rates at a constant superficial velocity the voldage profile along the riser becomes sharper. Different bed material sizes give voldage profiles that are different. At same operation condition, the smaller diameter solid particles yields a voldage profile along the riser that varies rather smoothly while the larger solids not only lead 
lower voldage but also a longer dense phase region. Figure 4.3 shows the variatione of riser voldage as a function of bed solids s12.

4.1.2. Varlation of the voldage Profile with superficial Gas Velocity

Figure 4.4 shows the test resulte at a constant supericial gas velocity of $2.65 \mathrm{~m} / \mathrm{s}$ for solide ofrculation rates of 16.86 $\mathrm{kg} / \mathrm{m}^{2} .8,18.30 \mathrm{~kg} / \mathrm{m}^{2}, 19.62 \mathrm{~kg} / \mathrm{m}^{2}$. and $22.93 \mathrm{~kg} / \mathrm{m}^{2}$. with particle diameter of $116 \mathrm{~mm}$. The voldage profiles of these tests exhibit a dense phase zone, transition zone, and a lean phase zone from bottom to the top of the rieer. The transition of voldage from the bottom of the riser to the top of riser ls smooth. Figure $4.5 \mathrm{gives}$ the test results at superficial gas velocity of $4.25 \mathrm{~m} / \mathrm{s}$, solids circulation rate of $22.46 \mathrm{~kg} / \mathrm{m}^{2} . \mathrm{s}$, and solids diameter of $247 \mathrm{\mu m}$. The voldage in lower part of the riser changes rather rapidly. Voldage has an almost constant value above 1 meter above the distributor plate. Above this point, there are no eignificant varlation in voldage along the riser. For smaller circulation rates, the voldage reaches a steady value earlier than that for larger solids circulation rate.

Figure 4.6 shows the test results at superficial gas velocity of $2.10 \mathrm{~m} / \mathrm{s}$, solids circulation rate of $9.30 \mathrm{~kg} / \mathrm{m}^{2} . \mathrm{s}$, and solids diameter of $247 \mu \mathrm{m}$. This result is different from last two. The superficial gas velocity is about half of that previous two cases. Hence, presence of very few solids in the upper portion of the riser is due to a lower axial momentum. The fact that particles 
toward upward and then fall down to the lower part of the rlser at a lower elevation. The voldage in the lower part of the riser is smaller and the voldage variation in lower portion of the riser is in a sharp contrast to the very large voldage (close to 1) in the upper portion. This flow resembles a turbulent fluidized bed mode.

From above Figures $4.4,4.5$ and 4.6 , it 1s clear that the voldage profile along clrculating fluidized bed riser changes when the mean gas velocity changed. The voldage proflle along riser become fuller with increasing superficial gas veloolty and the solids circulation rate is larger, the effect of the mean gas velocity on the gas velocity profile is smaller. This phenomena to apparent from the figures which show that the voldage profile along circulating fluidized bed riser becomes more blunt or "fuller" with the increasing mean gas velocity. If the superficial gas velocity is low enough, the voldage profile will develop to a turbulent fluidized bed mode that is a dense bed with lean free board.

4.4.3. Varlation of voldage Profile with solids circulation Rates

In a clrculating fluidized bed riser, voldage is not only a function of the mean gas velocity but also of the sollds clrculation rate. A core-annular flow structure is formed in the circulating fluidized bed riser. The central core region is dominated by a dilute upflowing suspension of solids flowing at higher velocities while annulus is occupled by a dense, downflowing solids suspension with relative lower velocities. The downflowing solids near the wall have the most significant influence on voldage 
proflle. It makes the voldage proflle sharper with increasing solids circulation rate. At a given superficlal gas velocity, the solids clrculation rate determines the flow structure of the annulus flow, the higher the solids clrculation rate, the stronger the annulus flow. A strong downflowing solids flow Increases solids concentration in the lower part of riser. That is higher solids circulation rates result in a lower voldage in lower part of the rieer. Meanwhile, at higher solids circulation rate operation condition more solids will be entrained in the fluidizing air and hence a lower voldage will be observed in the upper part of the riser. Figure 4.7 Figure 4.8 and Figure 4.9 show the experimental results of voldage profile at given gas velocity and different solids circulation rates. These figures indicated that the solids circulation rate in circulating fluidized bed plays a key role in the voldage profiles.

Figure 4.7 gives the test results at superficial gas velocity of $2.1 \mathrm{~m} / \mathrm{s}$ with solids diameter of $247 \mathrm{\mu m}$. The circulation rates changed from $9.30 \mathrm{~kg} / \mathrm{m}^{2} . \mathrm{s}$ to $11.60 \mathrm{~kg} / \mathrm{m}^{2} . \mathrm{s}$. For such a small superficial gas velocity, the solids circulation rate does not appear to have a significant effect on the voldage profile along the riser. The solids concentration apparently divided two zones -dense phase and lean phase. Most of the solids which were entrained by fluidizing air do not go into upper part of the riser but begin to fall down along the riser wall at a fairly short distance from the distributor. In the upper part of the riser there are very few solids and the voldage nearly is equal to 1. If the superficial gas velocity is increased the voldage along riser changes and the 
effect of solids circulation rate on the voldage profile along riser will be very signiflcant. Figure 4.8 shows that the voldage profiles at a superficial gas velocity at $4.25 \mathrm{~m} / \mathrm{s}$ with solids diameter of $247 \mu \mathrm{m}$. The solids circulation rates are $15.02 \mathrm{~kg} / \mathrm{m}^{2} . \mathrm{s}$, $18.73 \mathrm{~kg} / \mathrm{m}^{2} . \mathrm{s}, 22.46 \mathrm{~kg} / \mathrm{m}^{2} . \mathrm{s}$ and $27.12 \mathrm{~kg} / \mathrm{m}^{2} . \mathrm{s}$. The voldage changes caused by the effect of solids circulation rates on the voidage profile is stronger in the lower part of the riser than in upper portion. The transition from dense phase to dilute phase is much more smooth than in the cases shown in Figure 4.7. Using smaller diameter solids and higher superficial gas velocities solids circulation rate affects voldage profile rather differently. Figure 4.9 shows the results of tests at superficial gas velocity of 4.9 $\mathrm{m} / \mathrm{s}$ with solids diameter of $116 \mathrm{~mm}$. In the lower part (less than $1.5 \mathrm{~m}$ above the distributor) voidage is affected very minimally under different solids circulation rates. In the upper part of the riser, solids circulation rates changes result in a relative large voldage change. Solids go up into the upper part of the riser and then fall down because of the typical geometry of the riser and the hydrodynamics. However, the solids do not flow down to the bottom of the riser, instead only half way. Higher solids circulation rates result in more solids being transported in the manner discussed above.

4.4.4. Variation of Voldage Profile with Solids Diameter

The solids properties also affect the voldage profiles along the riser. The smaller solids have a less effect on the voidage profiles compared to larger solids. Figure 4.10 shows the results 
of tests using different diameter solid particles. The first one uses solids with a mean diameter of $116 \mu \mathrm{m}$ at superficial gas relocity of $2.65 \mathrm{~m} / \mathrm{s}$ and solids circulation rate of $16.86 \mathrm{~kg} / \mathrm{m}^{2} . \mathrm{s}$. The second set uses solids with a mean diameter of $247 \mu \mathrm{m}$ at a superficial gas velocity of $3.1 \mathrm{~m} / \mathrm{s}$ and a solids circulation rate of $15.02 \mathrm{~kg} / \mathrm{m}^{2} . \mathrm{s}$. It is clear that even though operating conditions do not vary much the voidage profiles along the riser are very different from each other. The terminal velocity of the larger solids is higher than that of smaller solids and hence a tendency to fall back down rather than upwards. This is probably one of reasons why larger solids result in smaller voidages. It should be pointed out that the outlet geometry of the riser could very likely be contributing to the falling down of the particles. Next set of experiments will involve a smooth transition from the riser outlet to the cyclone inlet.

\section{NOTATIONS}

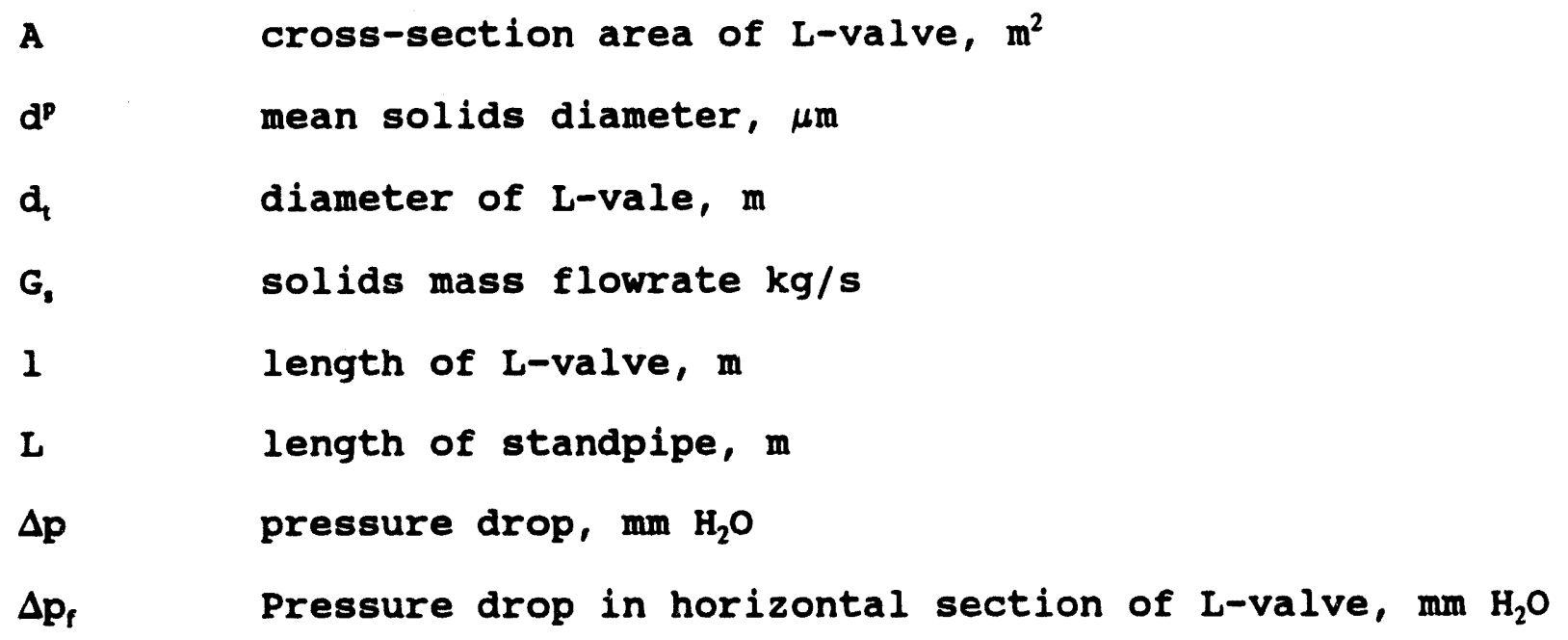




$\begin{array}{ll}u_{z} & \text { gas velocity } \mathrm{m} / \mathrm{s} \\ u_{3} & \text { solids velocity, } \mathrm{m} / \mathrm{s} \\ u_{r} & \text { relative velocity between gas and solids, } \mathrm{m} / \mathrm{s} \\ \epsilon & \text { voidage in the standpipe } \\ \mu & \text { viscosity of gas, } \mathrm{kg} / \mathrm{m} . \mathrm{s} \\ \rho_{k} & \text { gas density, } \mathrm{kg} / \mathrm{m}^{3} \\ \rho & \text { mean solids density, } \mathrm{kg} / \mathrm{m}^{3}\end{array}$




\section{BIBLIOGRAPHY}

Arena, U., Marzocchella, A., Massimilla, L. and Malandrino, A., (1992), "Hydrodynamics of Circulating Fluidized Beds with Risers of Different Shape and Size", Powder Technology, 70, pp. 237-247.

Bader, R., Findlay, J. and Knowlton, T.M., (1989), "Gas/Solids Flow Patterns in a $30.5 \mathrm{~cm}$ Diameter Circulating Fluidized Bed", Institute of Gas Technology, Sept. 25, 1989.

Barth, W., (1958), Chemie-Ing.-Techn, Vol. 30, 171.

Bernard, J.M., Wang, C.P. and Lee, R.M., (1981), "Measurement of Fluid Velocity in the Interior of a Transparent Fluidized Bed with a Laser Doppler Anemometer", AIChE Symp Ser, Vol. 77, No. 205, pp. 37-50.

Berruti, F. and Kalogerakis, N., (1989), "Modelling the Internal Flow structure of circulating Fluidized Beds", Can J Chem Eng, Vol. 67, No. 6, pp. 1010-1014.

Biswas, J. and Leung, L.S., (1987), "Applicability of Choking Correlations for Fast-Fluid Bed Operation", Powder Tech, Vol. 51, No. 2 , pp. 179-180.

Carey, V.P., (1987), "Dependance of settling Velocity on Particle Concentration in a Fluidized Bed of Spherical Particles", Int J Multiphase Flow, Vol. 13, No. 3, pp. 429-431.

Drahos, J., Cermak, J., Guardani, R. and Schugerl, K., (1988), "Characterization of Flow Regime Transitions in a circulating Fluidized Bed", Powder Tech, Vol. 56, No. 1, pp. 41-48.

Dry, R.J., (1986), "Radial concentrating Profile in a Fast-Fluidized Bed", Powder Tech, Vol. 49, No. 1, pp. 37-44.

Dry, R.J., (1987), "Radial Particle size segregation in a Fast-Fluidized Bed", Powder Tech, Vol. 52, No. 1, pp. 7-16.

Cox, C., Molodtsof, Y. and Large, J.F., (1989), "Control Mechanisms of Fluidized Solids Circulation Between Adjacent Vessels", AIChE J, Vol. 35, No. 12, pp. 1933-1941.

Grace, J.R. and Tuot, J., (1979), "A Theory for cluster Formation in Vertically Conveyed Suspensions of Intermediate Density", Trans I ChemE, Vol. 57, pp. 49-54.

Guilin, Y., Zhe, H. and Lianzhong, Z., (1984), "Radial Gas Dispersion in a Fast-Fluidized Bed", Fluidization, IV, pp. 145-152. 
Hartge, E., Li, Y., and Werther, J., (1986) "Analysis of the Local Structure of the Two-Phase Flow in a Fast Fluidized Bed", Circulating Fluidized Bed Technology, Pergammon Press, NY.

Herb, B., Dou, S., Tuzla, K., and Chen, J. C., (1992), "Solid Mass Fluxes in Circulatinf Fluidied Beds", Power Tech," Vol. 70, pp. 197-205.

Hinze, J.0., (1959,1971), Turbulence, McGraw Hill Book Co., New York.

Hirama, T., Takeuchi, H. and Chiba, T., "Regime Classification of Macroscopic Gas-Solid Flow in a Circulating Fluidized Bed Riser", Powder Tech., Vol. 70, 215-222.

Hjelmfelt, A.T. Jr. and Mokros, L.F., (1966), "Motion of Discrete Particles in a Turbulent Fluid", App Sci Res, Vol. 16, pp. 149-161.

Homsy, G.M., Jackson, R., and Grace, J.R., (1992), "Report of a Symposium on Mechanics of Fluidized Beds", J. Fluid Mechanics, vol. 236, pp. 477-495.

Horio, M., Ishil, H., Kobukai, Y. and Yamanishi, N., (1989), "Scaling Law for Circulating Fluidized Beds", J Chem Eng Jpn, Vol. 22 , No. 6, pp. 587-592.

Jackson, R., (1963), "The Mechanics of Fluidized Beds, Part II", Trans Instn Chem Engrs, Vol. 41, pp. 22-28.

Johnson, L.N., and Leone, F.C., (1964), "Statistics and Experimental Desion in Engineering and the Physical science", Vol. 1 , John Wiley \& Sons, Inc., N.Y.

Jurewicz, J.T., stock, D.E., Crowe, C.T. and Eschbach, J.E., (1975), "Measurement of Both Gas and Particle Velocities in Turbulent Two Phase Flow", proc of the Fourth symposium of Turbulence in Liquids, Rolla, Missouri.

Kale, S.R. and Eaton, J.K., (1985), "An Experimental Investigation of Gas-Particle Flows Through Diffusers in the Freeboard Region of Fluidized Beds", Int'l J of Multiphase Flows, Vol. 11, No. 5, pp. 659-674.

Kato, K., Shibasaki, Tamura, Anta, Wang and Takarada, (1989), "Particle Holdup in a Fast-Fluidized Bed", J Chem Eng Jpn, Vol. 22, No. 2 , pp. 130-136.

Kececioglu, I. and Keairns, D.L., (1989), "Computation of Solid Circulation Rates in a Fluidized Bed From Tracer Particle Concentration Distributions", Can J of Chem Eng, Vol. 67, pp. 290300 .

Kehoe, P.K.W and Davidson, J.F., (1971), "Continuously slugging Fluidized Beds", Inst Chem Eng symp Ser, Vol. 33, pp. 97. 
Kline, S.J. and MCClintok, F.A., (1953), "Describing Uncertainties in Single Sample Experiments", Kech Eng, pp. 3-6.

Knowlton, T., Findlay, J., sishtla, C. and Chan, I., (1986), "Solids Pressure Reduction Without Lockhoppers: The Restricted Pipe Discharge system", ATChE symp Ser, Vol. 83, No. 255, pp. $64-73$.

Knowlton, T.M., and Hirsan, (1977), "Solids Flow Control Using a NonMechanical L-Valve", Ninth synthetic Pipeline Gas symposium, Chicago, Illinois, Oct. 31 - Nov. 2, 1977.

Lanneau, K.P., (1960), "Gas-Solid Contacting in Fluidized Beds", Trans Inst Chem Enars, Vol. 38, pp. 25.

Lee, S.L. and Durst, F., (1982), "On the Motion of Particles in Turbulent Duct Flows", Int'l J Multiphase Flow, Vol. 8, No. 2, pp. 125-145.

Lee, S.L. and Srinivasan, J., (1978), "Measurement of Local Size and Velocity Probability Density Distributions in Two-Phase Suspension Flows by Laser Doppler Technique", Int'l J of Multiphase Elow, Vol. 4, pp. 141-155.

Levy, Y. and Lockwood, F.C., (1983), "Velocity Measurements in a Particle Laden Turbulent Free Jet", Combustion and Flame, Vol. 40, pp. 333-339.

Maeda, M., Hishida, $K$. and Furutani, T., (1980), "Velocity Distributions of Air-Solid Suspension in Upward Pipe Flow (Effect oi Particles on Air Velocity Distribution), Trans Japan Soc Mech Engrs, 46, p. 2313.

Martin, M.P., Turlier, P., and Bernard, J.R., (1992), "Gas and Solid Behavior in Cracking Circulating Fluidized Beds", Powder Technology, 70, pp. 249-258.

Mountzaris, T.J. and Jackson, R., (1986), "The Effects of Aeration on the Gravity Flow of Particulate Materials in Vertical

standpipes", AIChE symp ser, Vol. 83, No. 255, pp. 10-22.

Neale, G., Epstein, N. and Nader, W., (1972), "Creeping Flow Relative to Permeable spheres", Chem Eng sci, Vol. 28, pp. 1865-1874.

Richardson, J.F. and Zak1, W.M., (1954), "Sedimentation and Fluidization: Part I", Trans Inst Chem Eng, Vol. 32, p. 35.

Rhodes, M., Mineo, H., and Hirama, T., (1992), Particle Motion at the wall of Circulating Fluidized Bed", Powder Tech,, Vol.70, pp. 207-214.

Salem, T.F., and Gibbs, B.M. (1987), "Solid circulation Between Fluidized Beds Using Jet Pumps", Powder Tech, Vol. 52, No. 2, pp. 
107-116.

Shingles, T. and silverman, R.W., (1986), "Determination of Standpipe Pressure Proflles and silde Valve oriface Discharge Coeficients of synthol circulating Fluidized Bed Reactors", Rowder Tech, Vol. 47, No. 2, pp. 129-136.

Slack, G.W., (1963), "sedimentation of Compact clusters of Uniform Spheres", Nature, Vol. 200, pp. 466-467.

Slack, G.W., Jayaweera, K.O.L.F. and Mason, B.J., (1963), "The Behaviour of Clusters of spheres Falling in a Viscous Fluid: Part 1", I of Eluid Mech, Vol. 20, pp. 121-128.

Subbarao, D., (1986), "Clusters and Lean-Phase Behavior", Rowder Tech, Vol. 46, pp. 1.01-107.

Sutherland, K.S. and Tan, H., (1970), "Sedimentation of a Porous sphere", Chem Eng Sci, Vol. 25, pp. 1948-1950.

Taweel, A. M., Militzer, J., Kan, J. M. and Hamdullahpur, F., (1989), "Motion of Hydrodynamic Aggregates", Powder Tech,, Vol. 59, pp. 173-181.

Tchen, C.M., (1947), "Mean Value and Correlation Problems Connected with the Motion of Small Particles Suspended in a Turbulent Fluid", Ph.D. Dissertation, Delft, Martinz Nyhoff, the Hague.

Van Zoonen, D., (1962), "Measurement of Diffusional Phenomena and Velocity profiles in a Vertical Riser", Proc symp Interaction Between Fluid and Particles, Inst Chem Eng, pp. 64-17.

Wang, Z, Bai, D., and Jin, Y., (1992), "Hydrodynamics of cocurrent Downflow Circulating Fluidized Bed (CDCFB)", Powder Rechnelogy, 70, pp. 271-275.

Werther, J., (1991), "Particle Motion and Dispersion of Gas in Circulating Fluidized Beds", Symposium on Mechanics of Fluidized Beds, Stanford University, July 1-4, 1991 (Reported by Homsy et al., 1992).

Wen, C. Y. and Galli, A. F., (1971), In Fluidization, J. F. Davidson and D. Harrison, Eds., Acadmic Press, London.

Wirth, K.E., (1991), "Fluid Mechanics of circulating Fluidized Beds", Symposium on Mechanics of Fluidized Beds, stanford University, July 1-4, 1991 (Reported by Homsy et al, 1992).

Yang, W., (1983), "Criteria for choking in Vertical pneumatic Conveying Lines", Powder Tech, Vol. 35, pp. 143-150.

Yang, W., (1984), "Mechanistic Models for Transitions Between Regimes of Fluidization", AIChE J, Vol. 30, No. 6, pp. 1025-1027. 
Yerushalm1, J. and Cankurt, N.T., (1978), "Gas Backmixing in High Velocity Fluidized Beds", Eluidization, Cambridge Umv. Press, pp. 387-393.

Yerushalm1, J. and cankurt, N.T., (1979), "Further studies of the Regimes of Fluidization", Powder Tech, vol. 24, pp. 187-205.

Ylanneakis, M., (1987), "Velocity, Particle sizing and Concentration Measurement Techniques for Multiphase Flow", Powder Tech, Vol. 49, pp. 261-269.

Ylanneskis, $M$. and Whitelaw, J.H., (1984), Proc symp on Itoutd-solid Flow and Brosion wear in Industrial Equipment, ASME Fluids Engineering Conference, New Orleans, Fab. 11-17.

Yoshioka, S., Miyamoto, T., Tomura, J., Hirato, M., Kluchi, N. , and Ishiboshi, Y., (1987), "Circulatory Flow of Particles in a 0.96-m-dlameter Fluidized Bed", Int Chem End, Vol. 27, No. 2, pp. 281-287.

Yousfi, Y. and Gau, G., (1974), "Aerodynamique de L'ecoulement Vertical de suspensions Concentrees Gaz-Solides - I. Regimes D'ecoulement et stabilite Aerodynamic", Chem Eng Sci, Vol. 29, p. 139. 


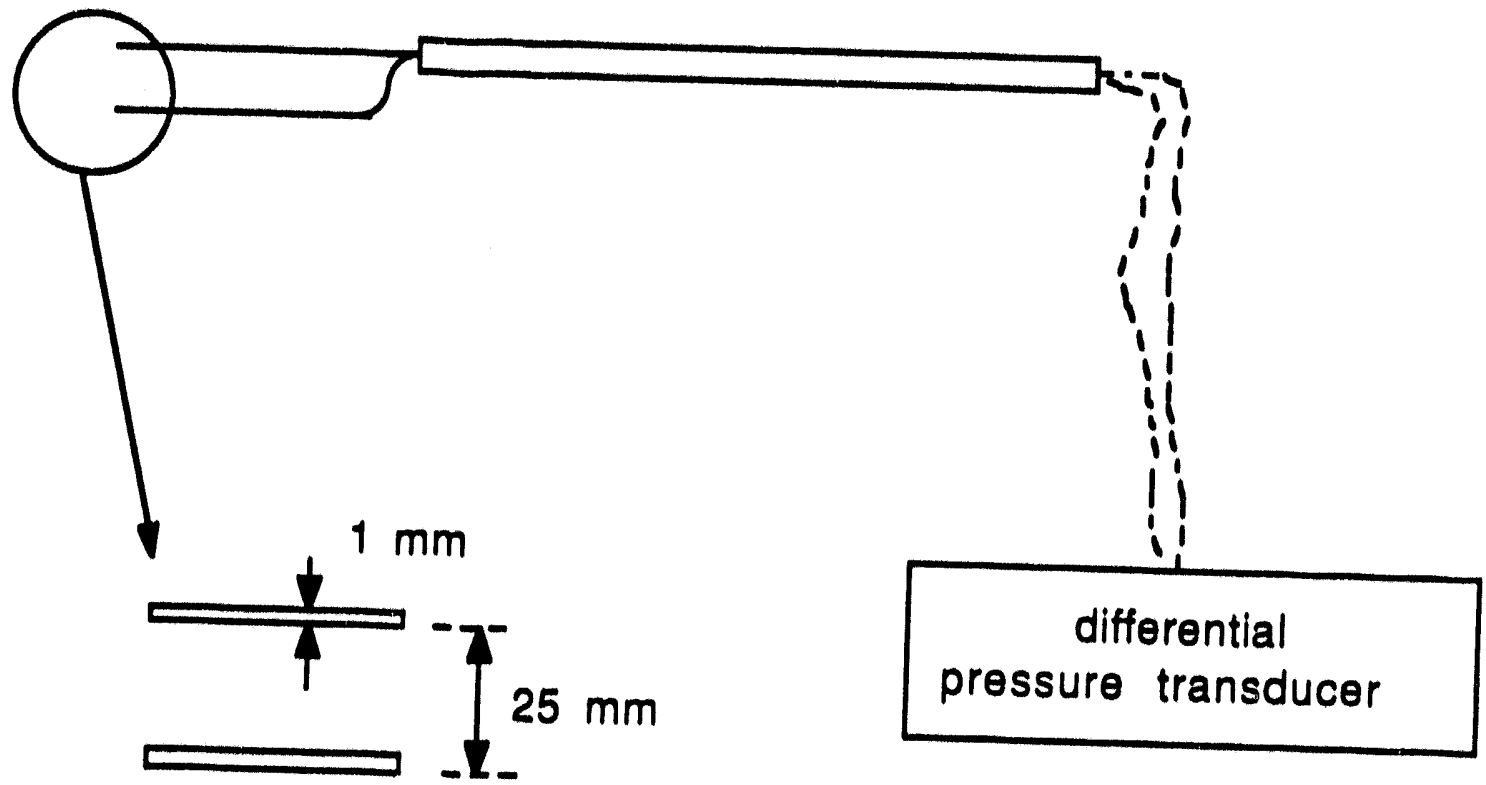

Figure 3.1 The Schematic of a Differetial Pressure Probe 


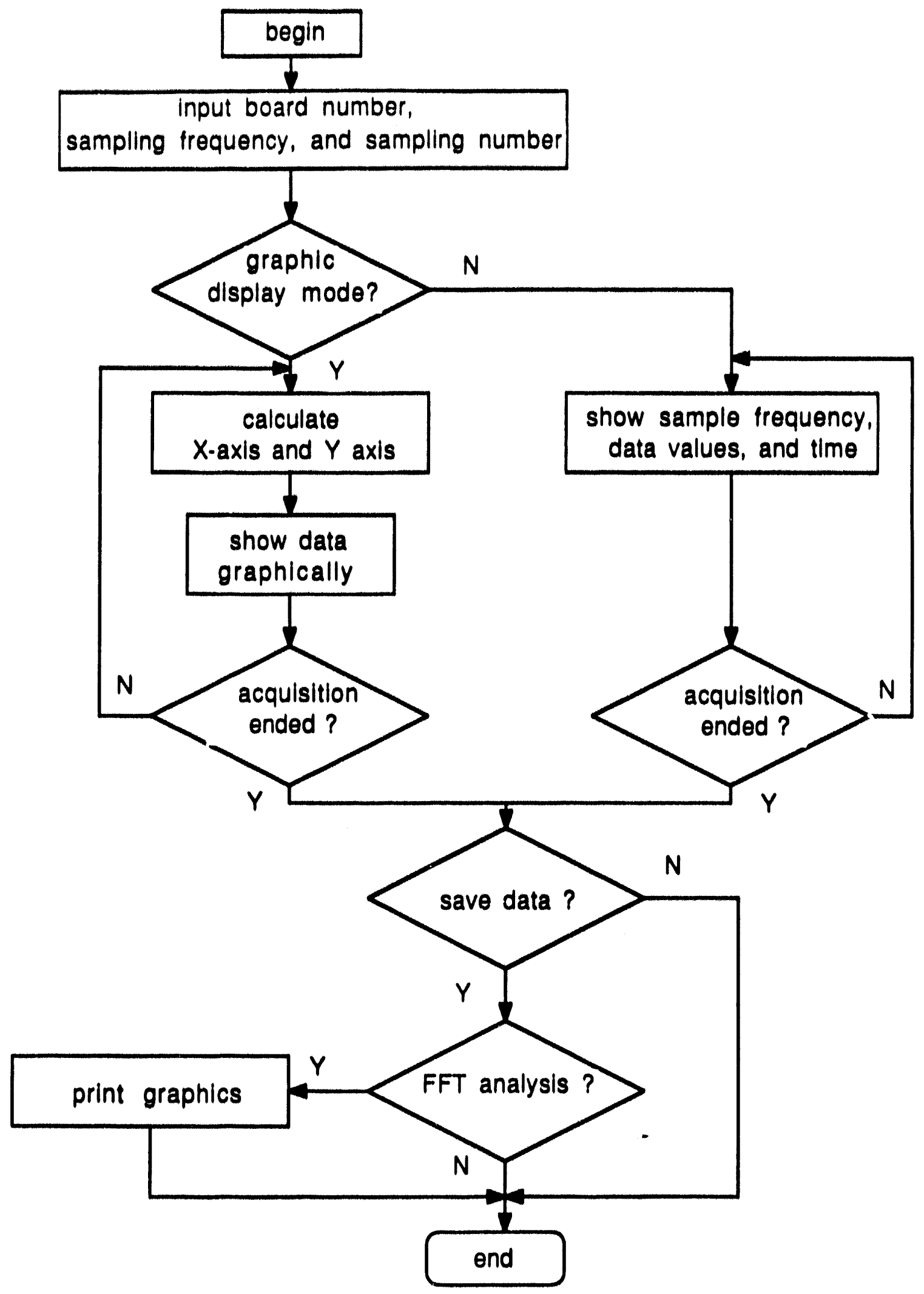

Figure 3.2 The Block Diagram of Software for Data Acquisition 


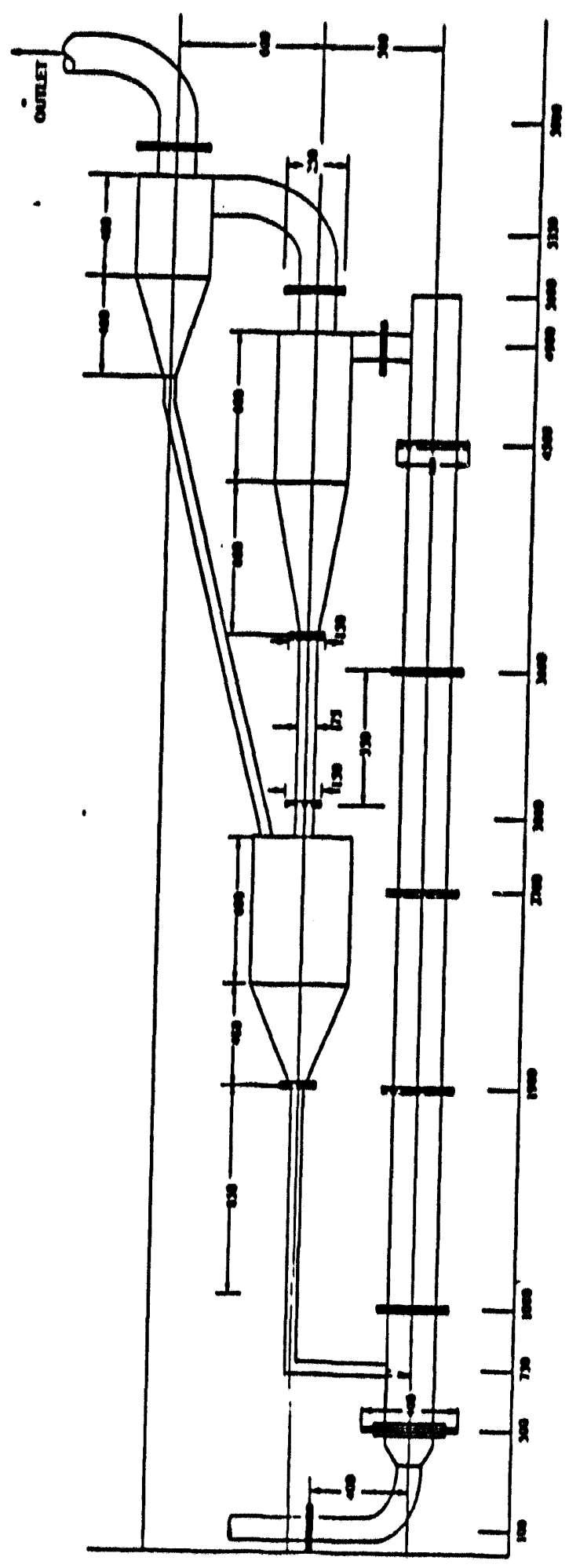

Figure 3.3 The Schematic of Circulating Fluidized Ded 


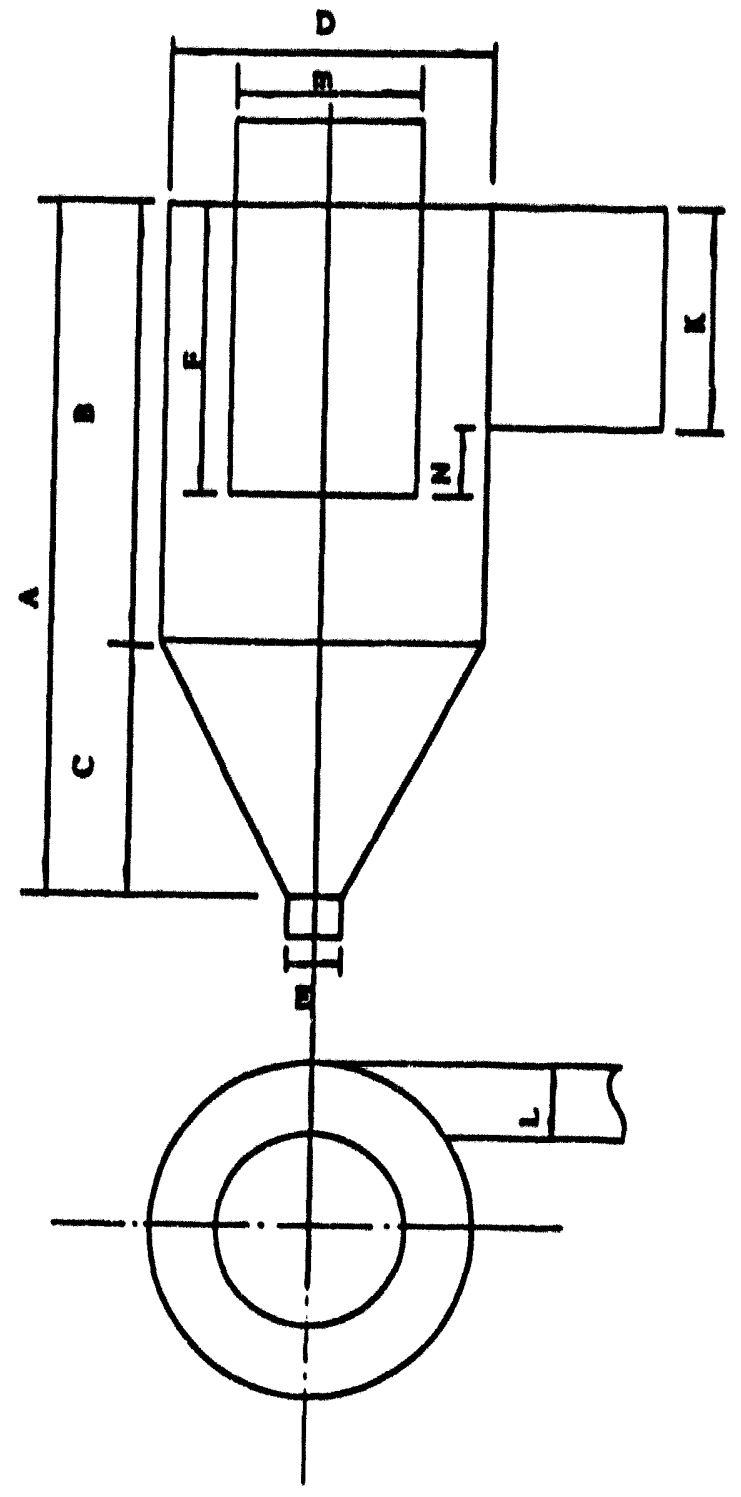

Figure 3.4 The Dimenatone of Cyolones 


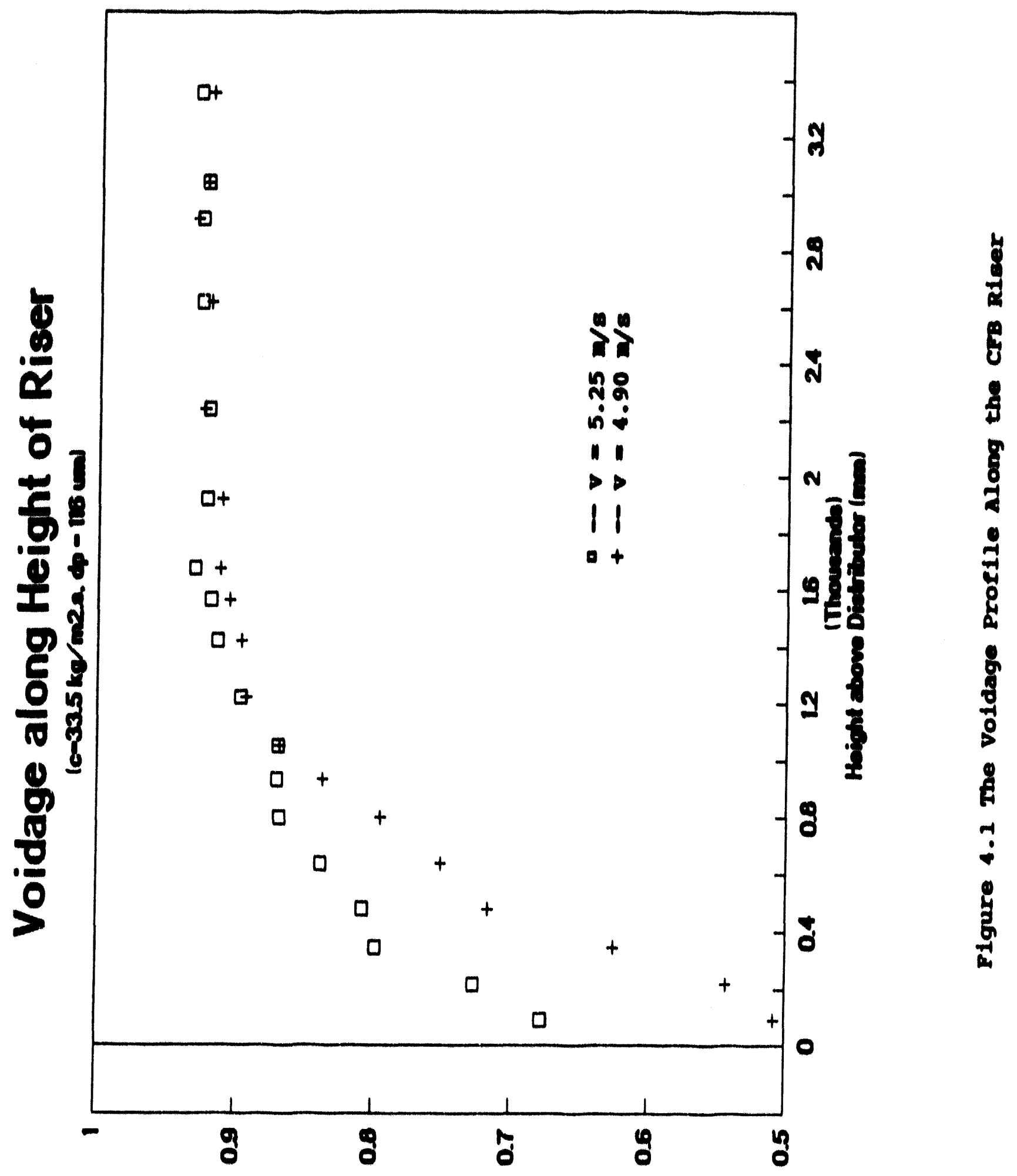




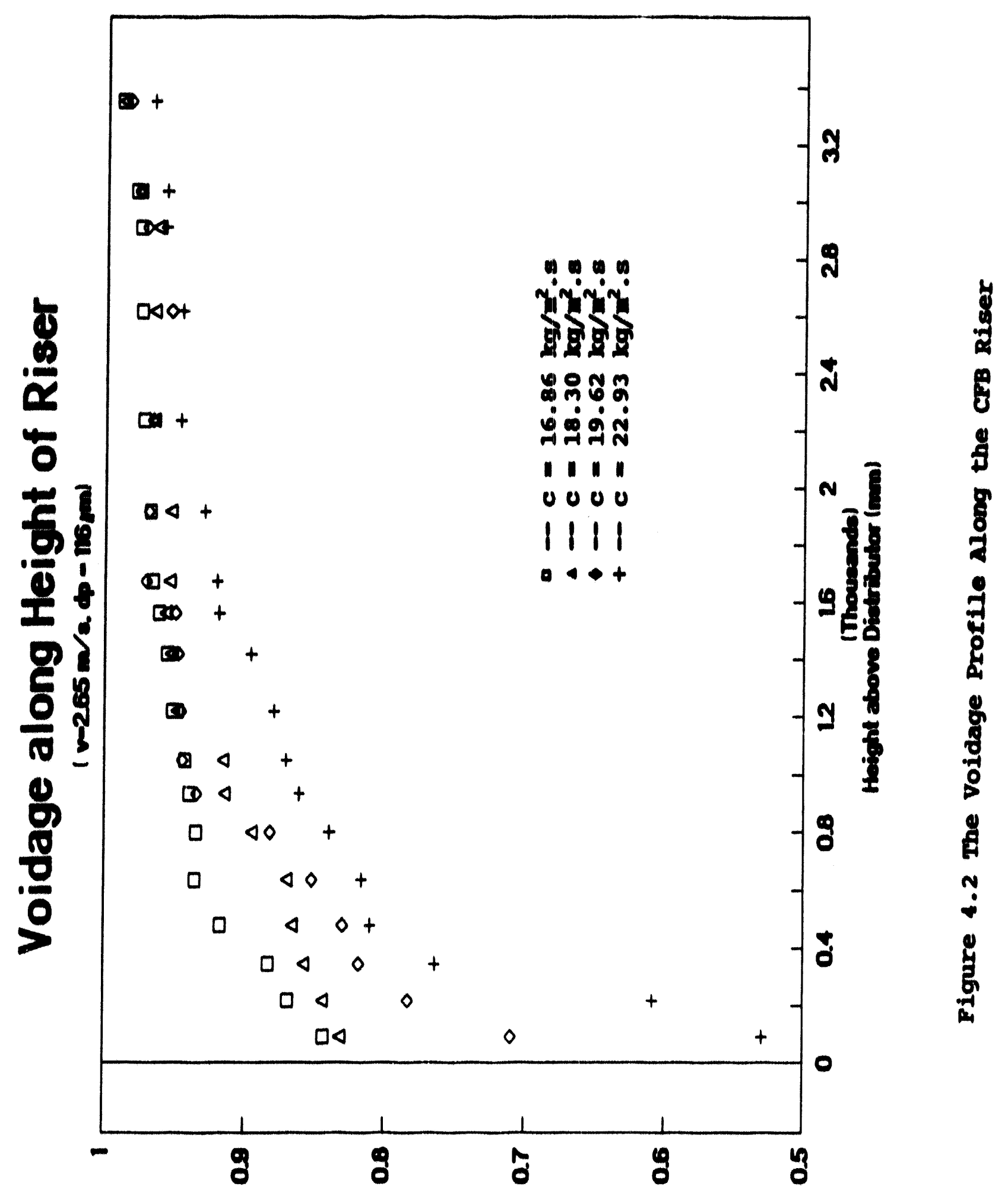




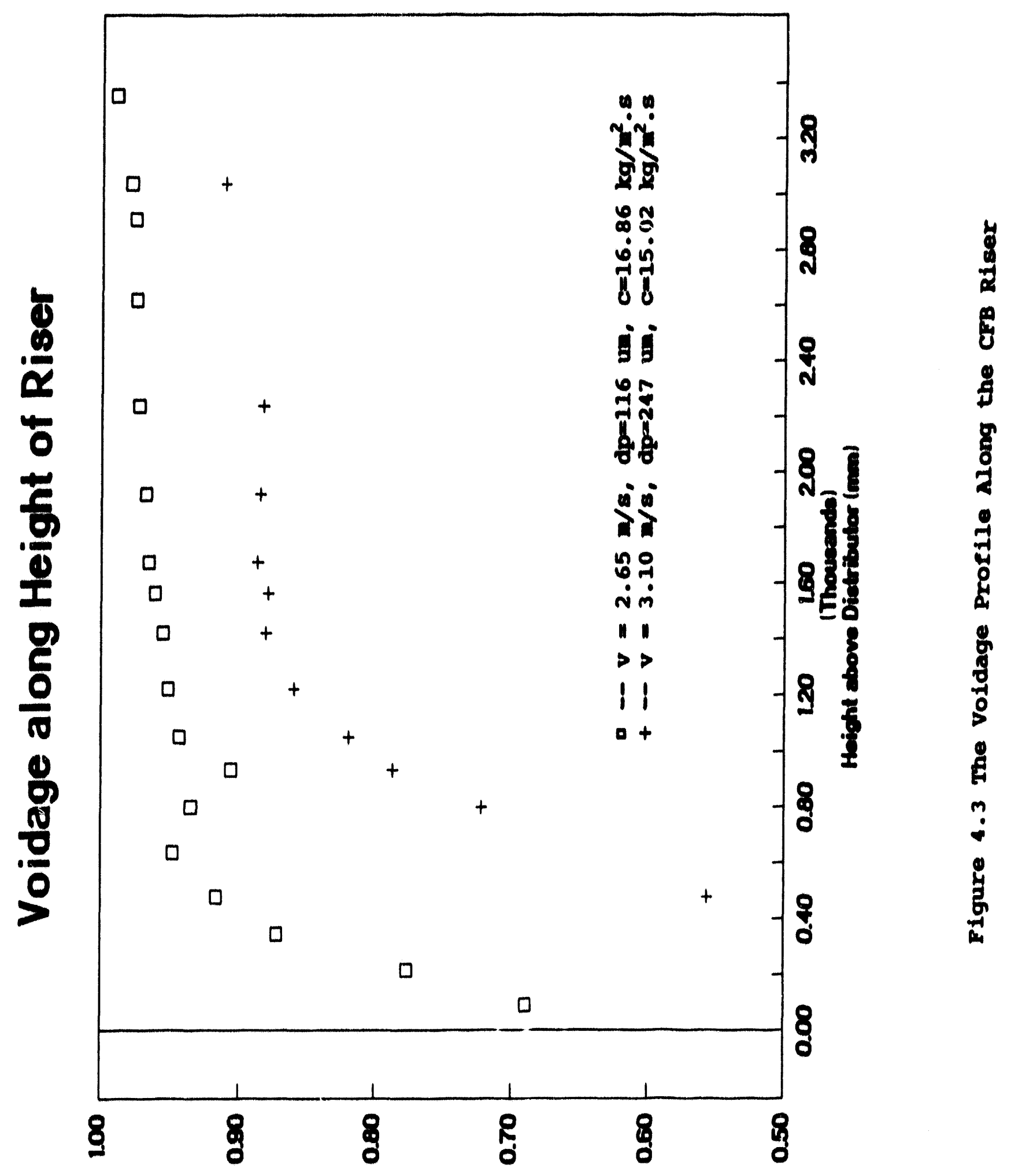




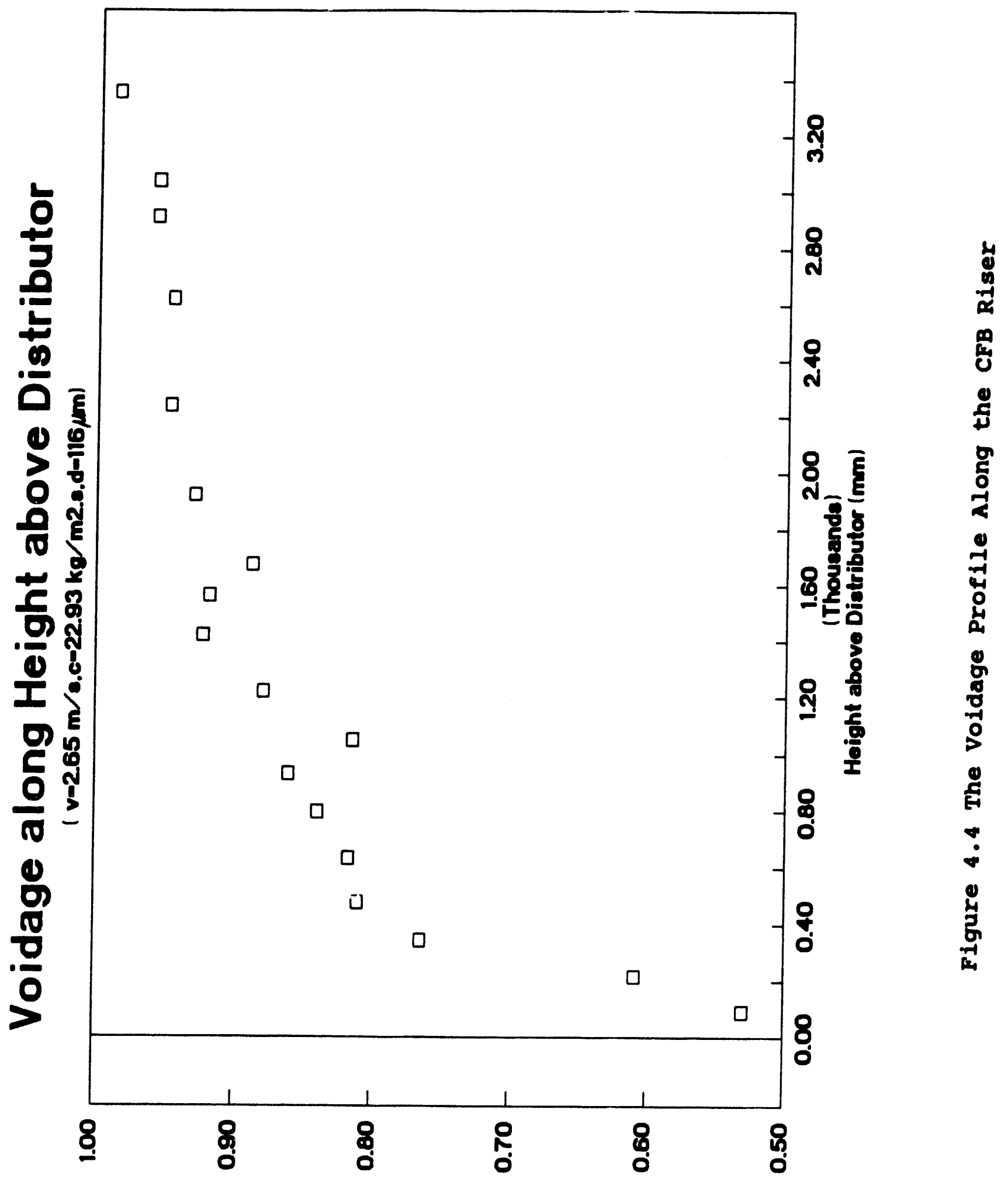

obep!on 


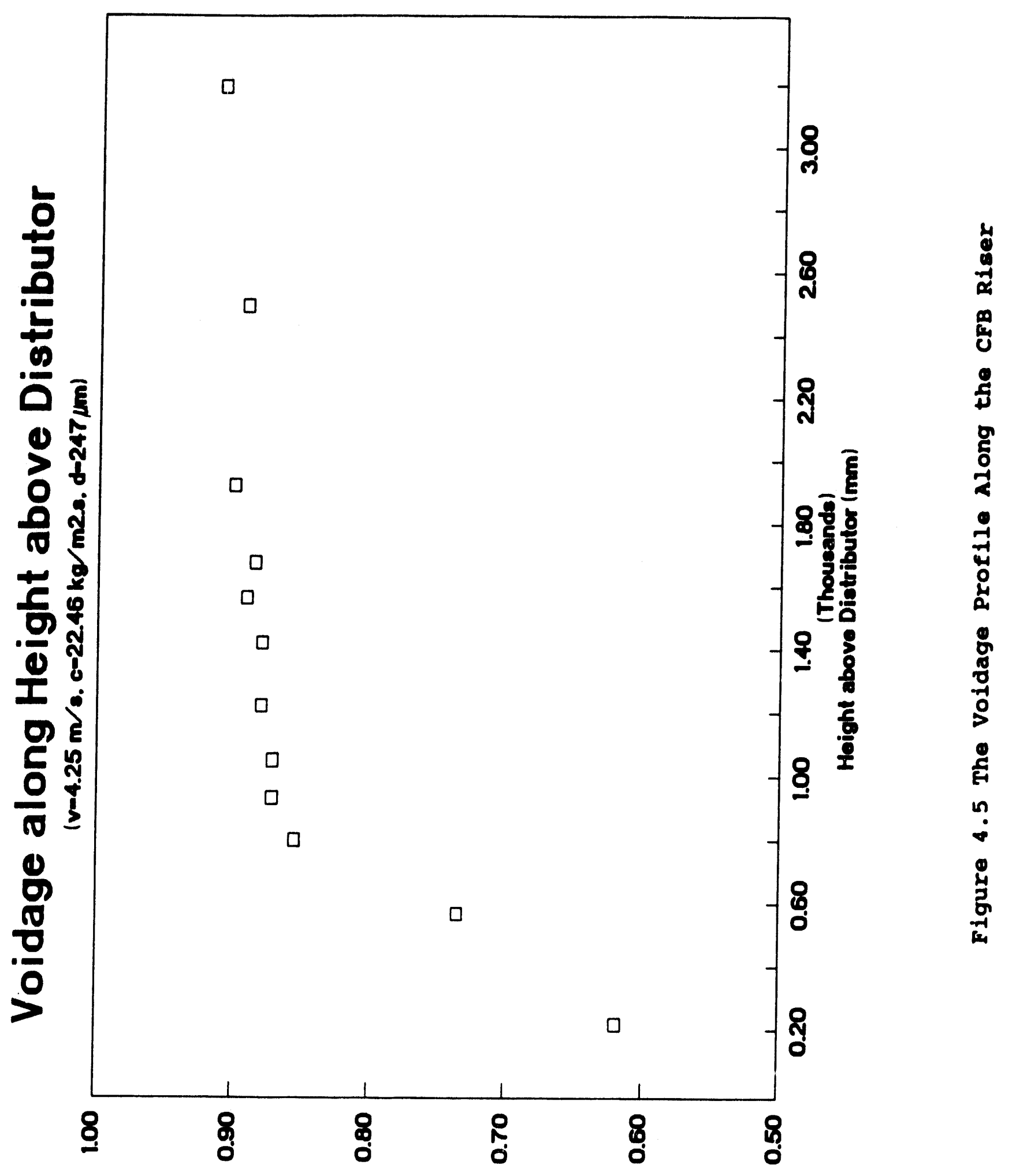




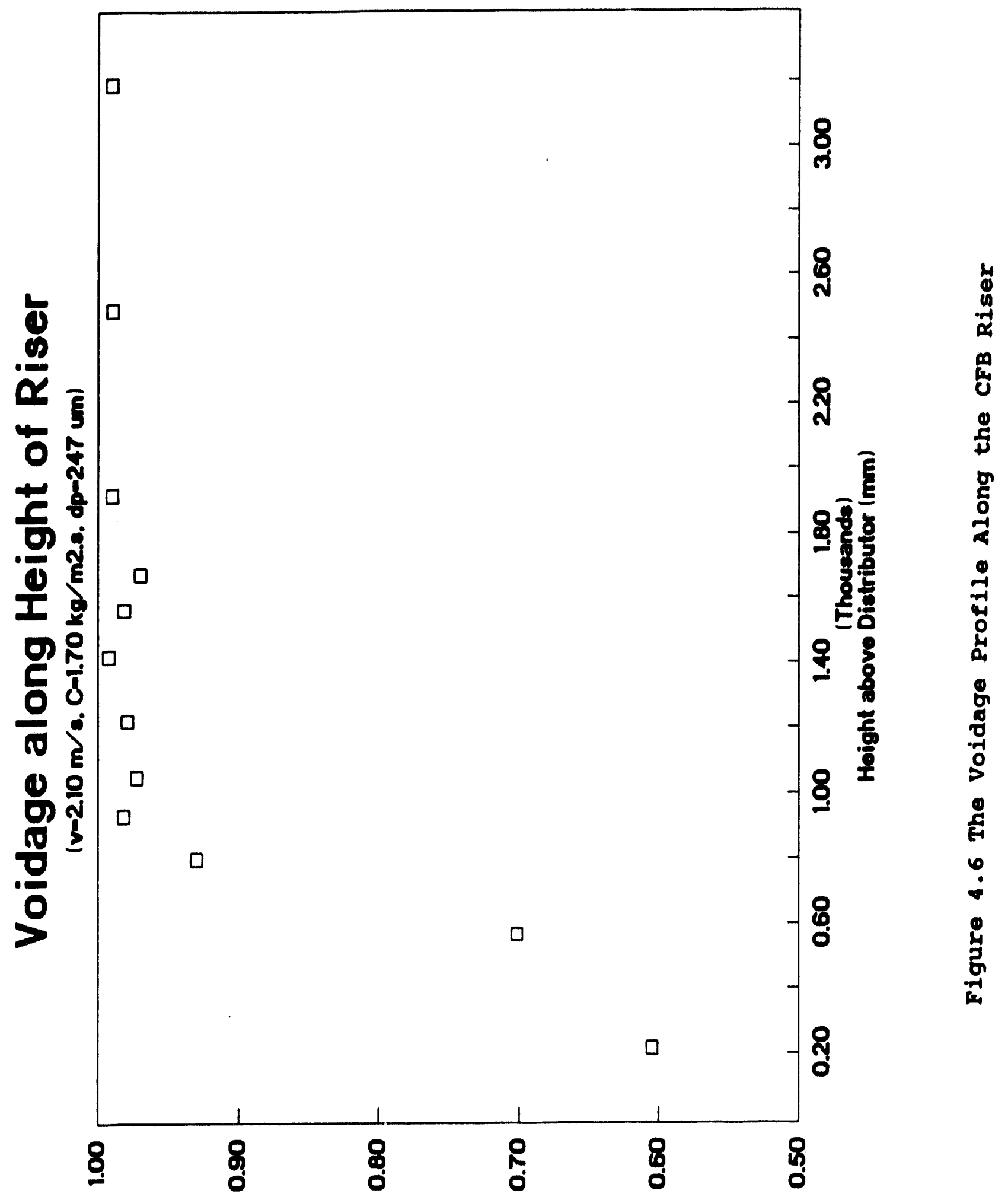




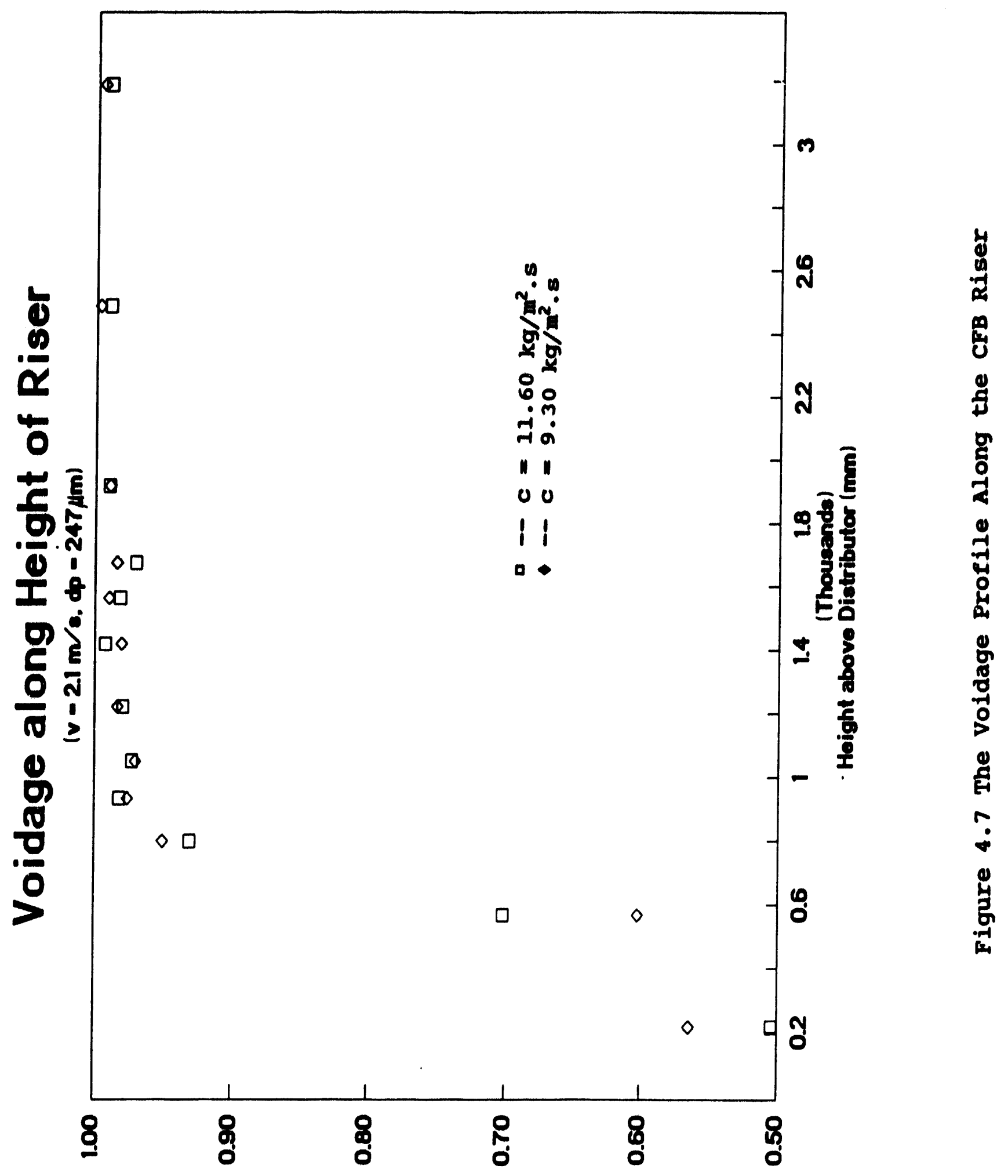




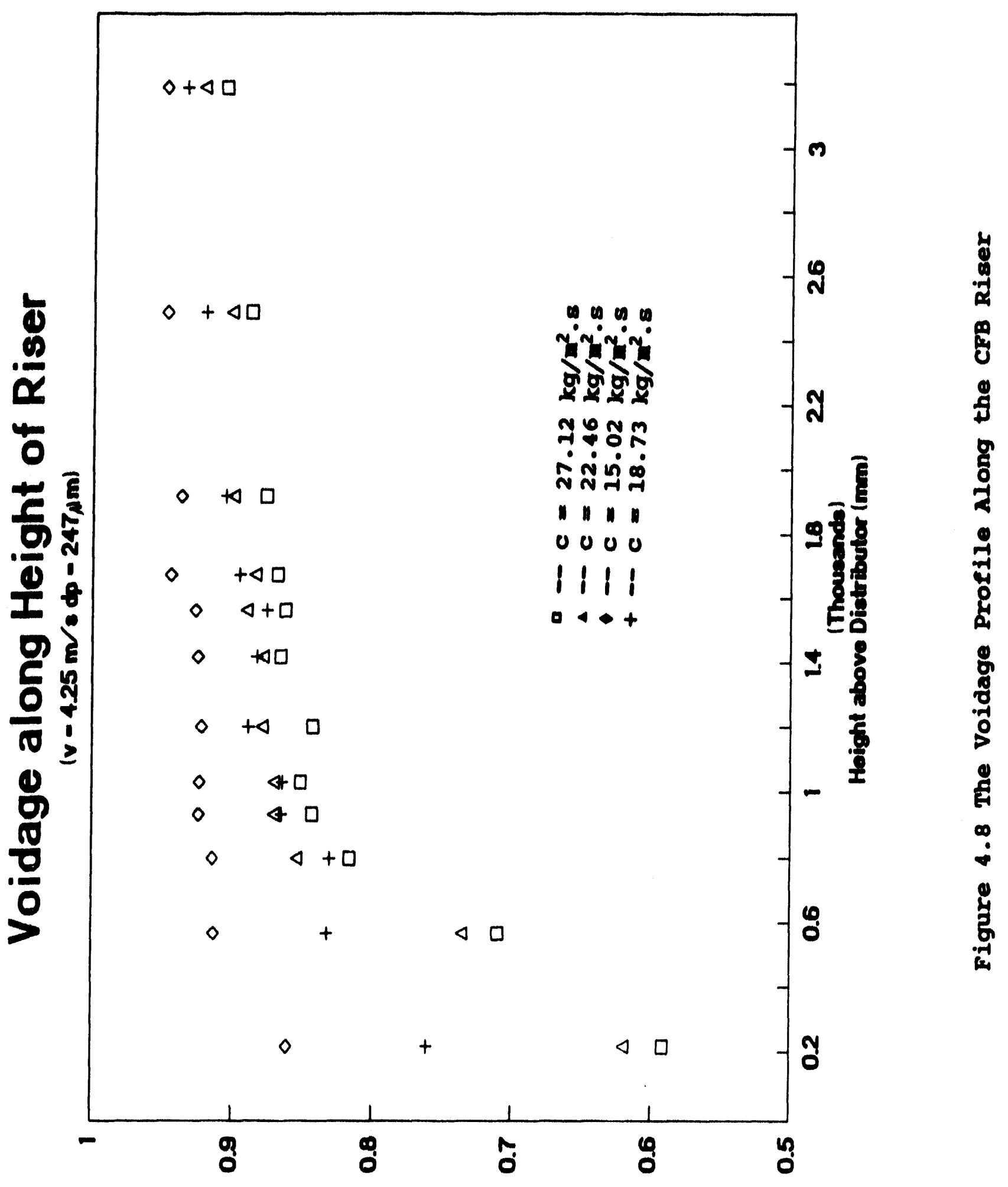




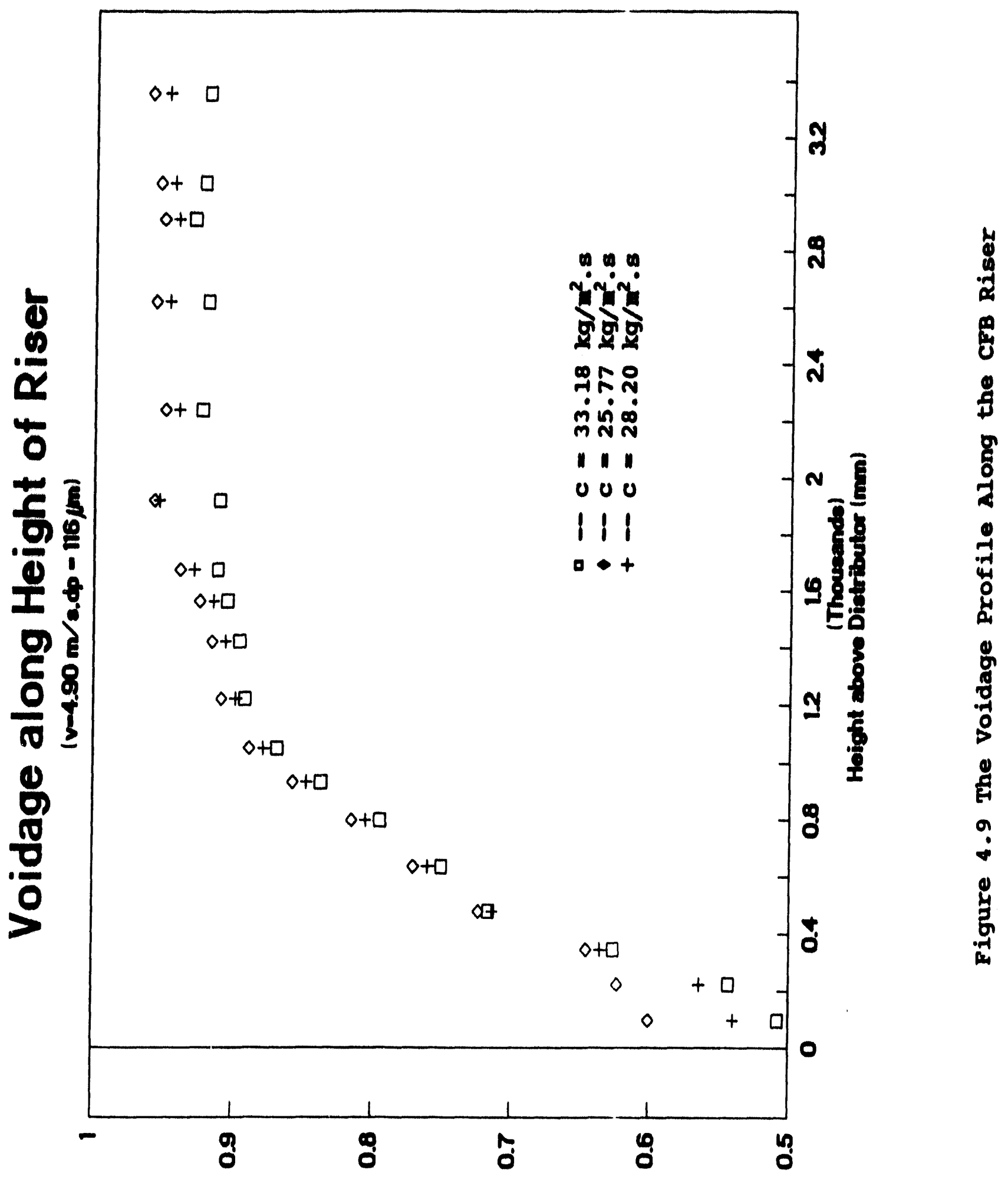




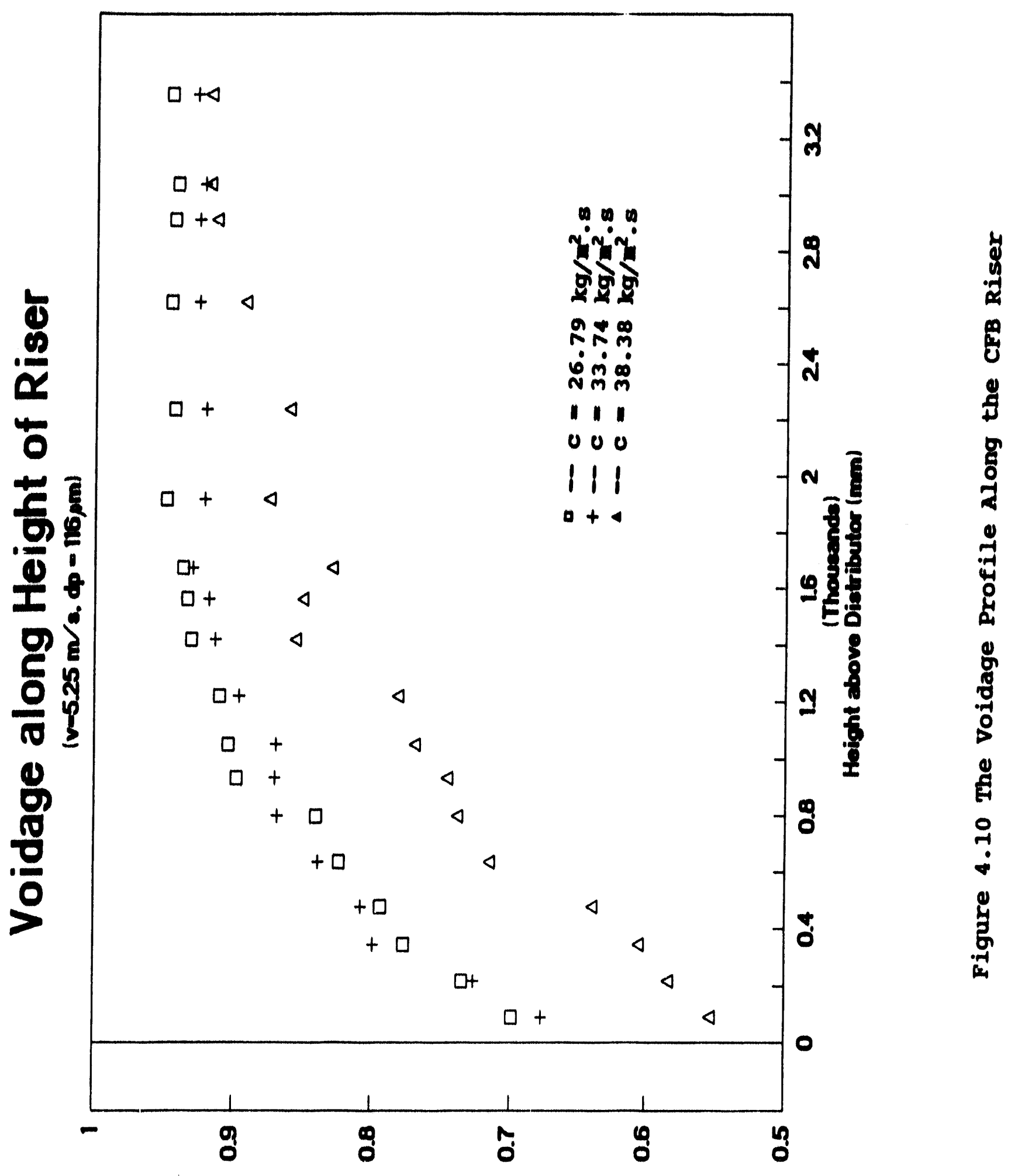



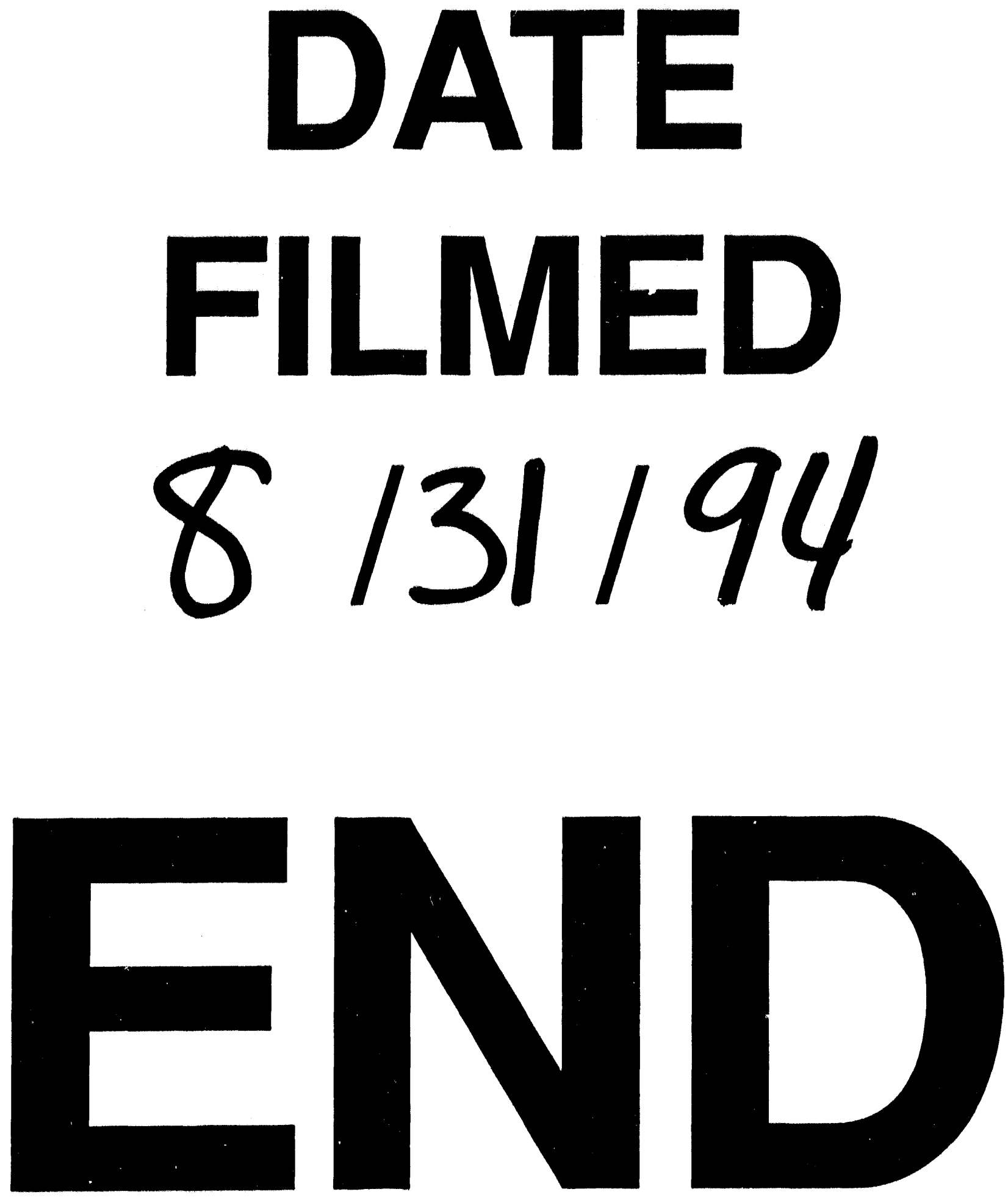


$$
2+\ln
$$

